

\section{DISCLAIMER}

This report was prepared as an account of work sponsored by an agency of the United States Government. Neither the United States Government nor any agency Thereof, nor any of their employees, makes any warranty, express or implied, or assumes any legal liability or responsibility for the accuracy, completeness, or usefulness of any information, apparatus, product, or process disclosed, or represents that its use would not infringe privately owned rights. Reference herein to any specific commercial product, process, or service by trade name, trademark, manufacturer, or otherwise does not necessarily constitute or imply its endorsement, recommendation, or favoring by the United States Government or any agency thereof. The views and opinions of authors expressed herein do not necessarily state or reflect those of the United States Government or any agency thereof. 


\section{DISCLAIMER}

Portions of this document may be illegible in electronic image products. Images are produced from the best available original document. 


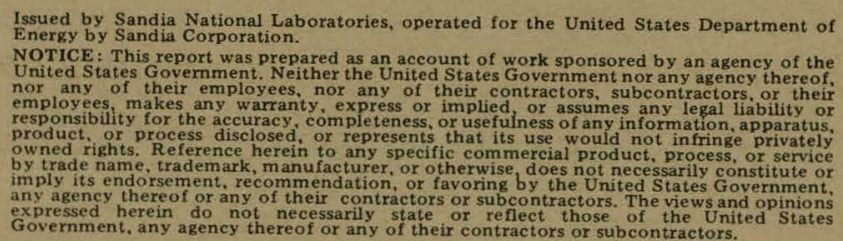

Printed in the United States of America

Available from

Na'sional Technical Information Service

U.S. Department of Commerce

5285 Port Royal Road

Springfield, VA 22161

Price: Printed Copy $\$ 5.25 ;$ Microfiche $\$ 3.00$ 


\section{PAGES 1 to 2 WERE INTENTIONALLY LEFT BLANK}


SAND80-2409

Urilimited Kelease

$\mathrm{UC}-52 \mathrm{~d}$

Printed November 1980

\title{
AN ACOUSTIC MEASUREMENT OF BOILING INSTABILITIES \\ IN A SOLAR RECEIVER
}

Alan G. Beattie

Sandia National Laboratories

Nondestructive Testing Technology Division 1552

Albuquerque, New Mexico 87185

\begin{abstract}
An acoustic technique was developed and used to search for boiling instabilities in the prototype receiver for the Barstow 10 MW Solar Thermal Pilot Plant. Instabilities, consisting of movements of the transition zone between regions of nucleate and film boiling, were observed. The periods of these fluctuations ranged between three and fifteen seconds with no indications of preferred frequencies. The peak tio peak amplitudes of the fluctuations averaged 0.4 meters under steady state conditions at absorbed power levels between 2.0 and $3.2 \mathrm{Mr}$. Transient fluctuations with amplitudes up to 2.0 meters were also seen. These transients usually lasted between 30 and 300 seconds. It was not possible to pinpoint the causes of these transients.
\end{abstract}

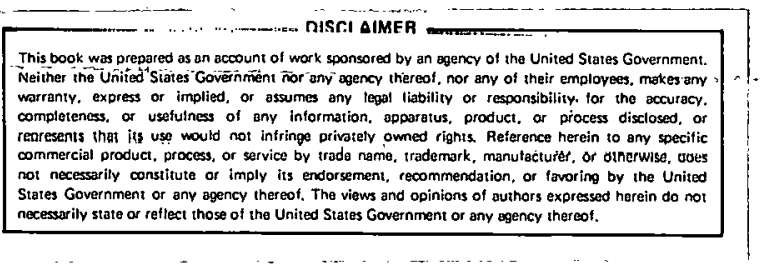

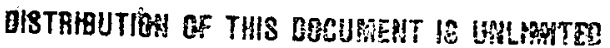




\section{ACKNOWLETUGME'NI'}

This experiment was made possible by the enthusiastic cooperation of the following two companies: Acoustic Emission Technology, who modified and reprogrammed their source location system for lease and then cheerfully put up with an incredible number of schedule changes; and Dunegan/Endevco, who designed and built the acoustic emission transducers specifically for this experiment and did it in record tine. Much of the supervision and work in the daily running of the data. acquisition system was ably carried out by Jean Kinker, Division 1552. 
TABLE OF CONTENTS

Page

Introduction

Pnysical Principles

9

Experimental Details

Data Analysis

20

Results and Discussion

Sidmmary and Conclusions .

References

\section{LIST OF FIGURES}

1. Solar Receiver for the Barstow Pilot Plant 14

2. Details of the Transducer and Mounting Stud 16

3. Layout of the Transducer Array on the Receiver 17

4. The Acoustic Power Distribution. Function $Y(y)$ with $r=20.0$ and $s=20.0$

5. 'The Acoustic Fower Vistribution Function $\mathrm{Y}(\mathrm{y})$ with $r=0.4$ and $s=2.1$

6. The Calculated Position of the Transition Zone Locus as a Function of' 'lime. 'l'he Unsmoothed curve for kun 410F'

7. The Calculated Position of the Transition Zone Locus as a Function of Time. Smooth Curve for Run $410 F$

8. The Peak to Peak Amplitude of the Fluctuations in the Transition Zone Locus as a Function of Time. Run $410 F$

9. Spectral Amplitudes of the Transition Zone Fluctuations f'or kun 41UH'. Flotted as a Hunction of the Feriod of the Fluctuations.

10. Transition Zone Position as a Function of Time for kun 3.2A 34

11. Transition Zone Position and Feed Water Flow as a Function of Time for Run 208A 
12. Transition Zone Position as a Function of Time for Run 410F 37

13. 'l'ransition Zone Position as a Function of Time for Run $410 G \quad 38$

14. Transition Zone Position as a Function of Time for Run $410 \mathrm{H} \quad 39$

15. Transition Zone Position as a Function of Time for the Pariod Covering Runs 4IOF, $410 \mathrm{G}$ and $4 \mathrm{IOH} 40$

16. The Peak to Peak Amplitudes of the Fluctuations for Run $410 \mathrm{G} 41$

17. The Peak to Peak Amplitudes of the Fluctuations for Run $410 \mathrm{H} \quad 1.2$

18. Receiver output Steam Temperatures in Tubes 1, 40 and 66 for Run 4 IOF

19. Output Steam Pressure, Feed Water Flow and Solar Flux Measured by an Epply Pyroheliometer for Run 4IOF

20. Spectral Amplitudes of the Fluctuations for Run $410 G \quad 47$

21. Spectral Amplitudes of the Fluctuations for Run $410 \mathrm{H}$

22. Average Spectral Amplitudes of Transition Zone Fluctuations tor the 9 Runs Taken on 5 March 1980 
Introduction

The solar receiver for the Barstow $10 \mathrm{MW}$ solar thermal pilot plant differs in several significant ways from a conventional steam boiler. This receiver is heated from one side only and heat transfer is strictly by the absorption of radiant energy. The intensity of this radiant energy is not constant and can have fluctuations on a relatively short time, sçale. Convective and radiative cooling of the receiver oscurs simultaneously with the radiative heating. Furthermore, this cooling can change abmuptly as the wind changes direction or speed. The possible interactions of these and other conditions with the inherent instabilities ${ }^{l}$ in small diameter heated water-filled tubes cannot be accurately predicted.

Two different experiments ${ }^{2,3}$ on small heated tubes indicated that the position of the transition region between nucleate and film boiling could fluctuate in the tube under steady state conditions. A theoretical study ${ }^{1}$ was made which supported these observations. This study also showed that the life span of the receiver could be reduced by thermal fatigue caused by these fluctuations in the transition zone position. The exact life span will depend both on the fatigue characteristiçs of the metal and the amplitude and frequency of the fluctuations.

The prototype receiver for the Barstow $10 \mathrm{MN}$ plant was scheduled to be tested at the Albuquerque Central Receiver Test Facility to determine the necessary control criteria. It was decided that a measurement of these possible boiling instabilities should be made at the 
same time, if possible. For high frequency fluctuations such as those seen in the two experiments (periods of two to ten seconds), the temperature variation on the outside of the tubes will be much less than the variation on the inside of the tubes because of the effective thermal time constant of the tubes. Rather than breaching the integrity of the tubes to place a thermocouple on or near the inside surfaces, other methods of measurement were investigated. Calculations with a computer model of the receiver indicated that an acoustic technique would have a good chance of measuring the position and movement of the transition zone in the receiver. Based on these calculations, the decision was made to attempt this acoustic measurement during the testing of the prototype receiver.

This paper describes the acoustic measurement of the boiling instabilities in the prototype Barstow receiver and gives the final results. These results show that the locus of the transition zone can move with a peak to peak amplitude of up to two meters and wi.th porinds between three and flfteen seconds. Even under quiescent steady state conditions there are background fluctuations with peak to peak amplitudes of 0.4 meters. These fluctuations appear to be a coherent movement of the transition zone and not independent movement in each tube. It is thought that these results are characteristic of the general receiver design or control system and are not limited to the specific conditions of the analyzed tests. However, it must be noted that neither the control of the receiver nor the configuration of the receiver during the final high power tests were identical to those proposed for the Barstow Pilot Plant. 


\section{Physical Principles}

Water flowing through a heated tube quietly absorbs heat until the water reaches a temperature, depending on the pressure, where nucleate boiling starts. This is normal boiling, characterized by the formation of small gas bubbles with the inside of the tube still being wet by the water. At some critical point, the combination of water temperature and heat flux produces a film of steam on the inside of the tube. While there still may be liquid water inside the tube, the surface of the tube is no longer wet. This film boiling then proceeds until all liquid water is converted to steam, after which the steam begins to superheat. The transition between nucleate and film boiling is not sharp in space as there will be filaments of water wetting the walls in the film boiling region and bubbles of steam next to the walls in the nucleate region. Still, it is reasonable to assume that the transition region should not be a large number of tube diameters in length. Thus, even for ten or twenty tube diameters ( 7 to $14 \mathrm{~cm}$ ), the extent of the transition region is quite small compared to the dimensions of the raceiver.

The difference in heat transfer rate between a wetted surface and one with a film of steam between the metal and the water can be quite large. Estimates ${ }^{I}$ of the difference of the inner tube wall temperature between adjoining areas of nucleate and film boiling are as high as $80^{\circ} \mathrm{C}$ for the operating conditions of the Barstow recelver. If a boiling instability causes the transition region to move up and down the tube, the changing temperature will cause thermal fatigue. To determine whether this could have a serious effect on the life span of 
the receiver, one must have some knowledge of the amplitudes and frequencies of any fluctuations in the transition zone locus produced by boiling instabilities.

For a single tube, the transition region is well defined but for a receiver composed of many tubes, it is not obvious that there is a transition zone for the receiver. The two limiting cases of this type of boiling instability in a receiver are first, the locus of the transition region in each tube moves totally independent of the motion in any other tube, and second, the transition regions in all the tubes move together in a coordinated motion. While both types of instability will be considered, the acoustic measurement technique assumes that there is a transition zone in the receiver which implies that the movements in most of the tubes are in phase.

Almost everyone is aware that nucleate boiling produces a,romstis noise. Simple experiments at one atmosphere showed that the frequency content of this noise extended to above $400 \mathrm{kHz}$. Acoustic signals are easily transmitted through a water-metal interface. However, much less acoustic energy is transmitted through a water-steam-metal interface. A simple calculation, based only on relative acoustic impedances, shows that the acoustic intensity transmission coefficient for the steam film interface is six orders of magnitude less than that for the wetted metal interface. While this calculation is far too simple for the frequencies and geometry involved in the receiver, it does indicate the qualitative difference between the two interfaces. With this difference in mind, we can model a heated tuke with water flowing through it as an extended acoustic noise source, starting at the onset of nucleate boiling 
and continuing to the transition region. In the region of nucleate boiling the acoustic coupling between the water and the tube is large. Beyond the transition region even though noise may be generated, there is effectively no coupling between the water and the tube.

The acoustic noise produced by nucleate boiling consists of many small impulses caused by bubble initiation and possibly also by bubble collapse. If the boiling is vigorous or extended, these impulses overlap and the signal has the characteristics of white noise with a high frequency cut off. The only-information contained in this signal is its power. Amplitude, phase and time information of the original acoustic. impulses are lost in the physical summing of the impulse signals.

For a single heated pipe with water flowing through it, we can locate the transition region by sampling the acoustic amplitude at two locations. We will assume that steady state conditions have been reached and that the circuitry measuring the acoustic amplitudes has an averaging time that is Iong compared to the period of the random variations in the acoustic amplitude. The equations which must be solved are then

$$
A_{i}{ }^{2}=A_{0}^{2} \int_{0}^{C} Y(y) e^{-2 Q^{\prime}\left(y-v_{i}\right)} d y
$$

where the $A_{i}$ are the measured signal amplitudes at the transducer coordinates, $V_{i}, \beta$ is the acoustic attenuation of the tube and $A_{0}{ }^{2} Y(y)$ is a function describing the distribution of the acoustic signal power along the tube from the start. of the tube to the location of the transition region, $C$. If we can guess the shape of the function $Y(y)$, then the two unknowns are $A_{0}$ and $C$. These equations contain the implicit assumption that no acoustic noise is transmitted into the tube beyond 
the point $C$, either because it is not generated beyond that point or because of the very poor acoustic coupling of the water-steam-metal. interface.

The simultaneous solution of these two equations will give the location of the transition region. The exact calculated position of the transition region, $C$, will depend on the specific shape of the acoustic power distribution function $\mathrm{Y}(\mathrm{y})$. However, determination of the relative position as a function of time of the transition region, which is the gual of the measurement, wi.l1 he essentially indepcndent of the exact shape of $Y(y)$ as long as it is reasonably close to the actual power distribution.

The actual receiver has the form of a plate composed of 70 tubes lying side by side, welded together. Equation (1) can easily be extended to two dimensions. However, the design of the receiver suggestis strongly that the acoustic attenuation will be anisotropic. The two dimensional equations are then

$$
A_{i}^{2}=A_{0}^{2} \int_{-i}^{+a} \int_{0}^{C} X(x) Y(y) e^{-r\left(\underline{\alpha}^{2}\left(x-W_{i}\right)^{2}+\beta^{2}\left(y-V_{i}\right)^{2}\right)^{I / 2}} d y d x
$$

where $\pm_{a}$ are the horizontal, $x$, dimension of the receiver, $X(x)$ is the horizontal acoustic power distribution function, $\alpha$ is the horizontal acoustic attenuation in the receiver and $w_{i}$ are the horizontal transducer coordinates. The $Y$ direction is the vertical direction and the origin of the coordinate system is at the bottom center of the receiver. It can be seen that while this extension to two dimensions does not increase the number of unknowns, it does complicate the 
equations. Unlike Equation (1), Equation (2) is not analytically integrable. In addition, the assumption has been introduced that the locus of the transition region is a horizontal line on the receiver. While this set of equations is still physically correct, the assumptions that had to be made seriously limit their usefulness in a real experiment. There is no reason to believe that the locus of the transition must be a horizontal straight, as opposed to a curved, line. There are now two power distribution functions to guess and an attempt to filter the high frequency fluctuations out of the acoustic amplitudes may remove the information being sought.

A solution to these problems is to use many equations instead of just two and calculate a best fit solution to these many equations instead of an exact solution to two equations. Thus, there can be some error in the form of the power distribution functions and some random noise in the measured acoustic amplitudes without having any large effect on the solution to the set of equations. Finally, the locus of the transition zone now becomes an average vertical position. After some computer modeling, a set of twenty equations was decided on as a good compromise between expense (both of computation and equipment) and accuracy.

Experimental Details

A drawing of the prototype receiver is shown in Figure 1. This receiver consists of seventy tubes welded together to form a plate $17.0 \mathrm{~m}$ long and $0.9 \mathrm{~m}$ wide. The tubes are Incoloy 800 with an O.D. of $1.27 \mathrm{~cm}$ and an I.D. of $0.69 \mathrm{~cm}$. These tubes are connected by manifolds at both ends of the receiver. Provisions were made for flow 


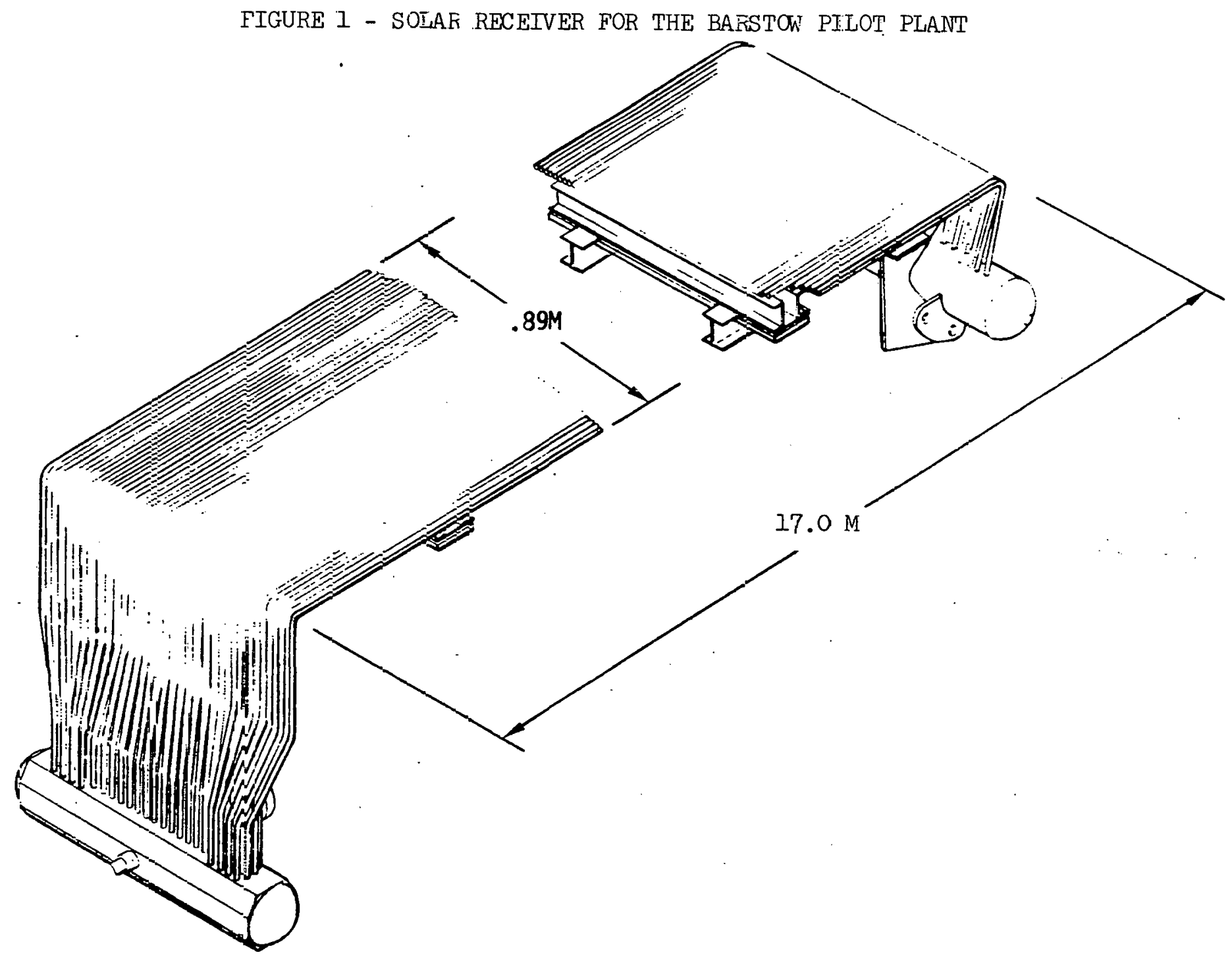


controlling orifices where the tubes join the manifolds. The actual pilot plant receiver will be 12.5 meters long so the bottom 4.5 meters of the prototype receiver were shielded from the sun. For the purposes of this experiment the receiver was assumed to be 12.5 meters long with the bottom at the point where it was first exposed to the sun.

The acoustic transducers were mounted on the rear of the receiver tubes. Small incoloy studs were welded. to the tubes and the transducers screwed into them as shown in Figure 2. To insure a good acoustic bond, a paste of $50 \%$ In and $50 \%$ Ga was applied between the transducer and stud surfaces. This paste wet both surfaces and easily lasted the life of the experiment.

The transducers were designed specifically for this experiment by Dunegan-Endevco Corp. and are now available commercially as model S9205-M4. They have a frequency response of 100 to $300 \mathrm{kHz}$ and no change in sensitivity up to $540^{\circ} \mathrm{C}$. There is a decrease in sensitivity between $540^{\circ} \mathrm{C}$ and their rated maximum operating temperature of $650^{\circ} \mathrm{C}$ due to increasing electrical conductivity in the ceramic. Nineteen of the twenty transducers survived a year on the receiver with many temperature excursions to $750+^{\circ} \mathrm{C}$. The other transducer failed because a crack in the stainless steel coaxial cable allowed the magnesium oxide insulation to absorb ethylene glycol which shorted the cable when it was heated.

The transducers were distributed over the back of the receiver in the pattern shown in Figure 3. The originally planned symmetric pattern evolved into this distribution because of the necessity of avoiding the receiver support structures. After the transducers were in place, six 


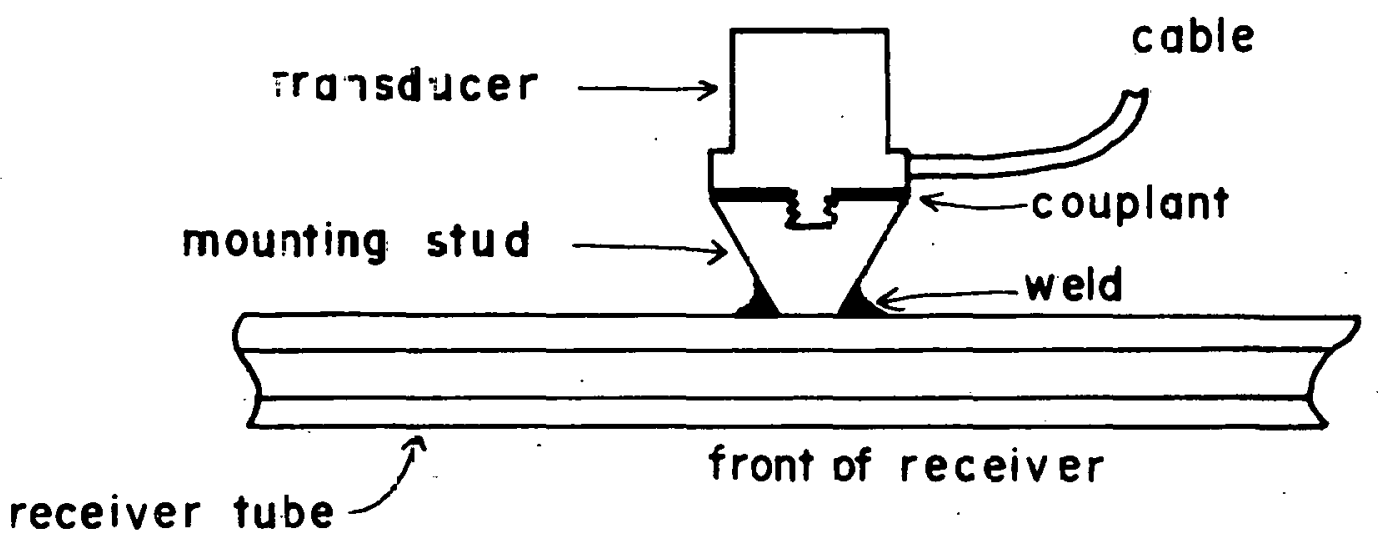


FIGURE 3 - LAYOUT OF THE TRANSDUCER ARRAY ON THE RECEIVER. THE HORIZONTAL DTMENSION HAS BEEN MAGNIFIED FOR CLARITY.

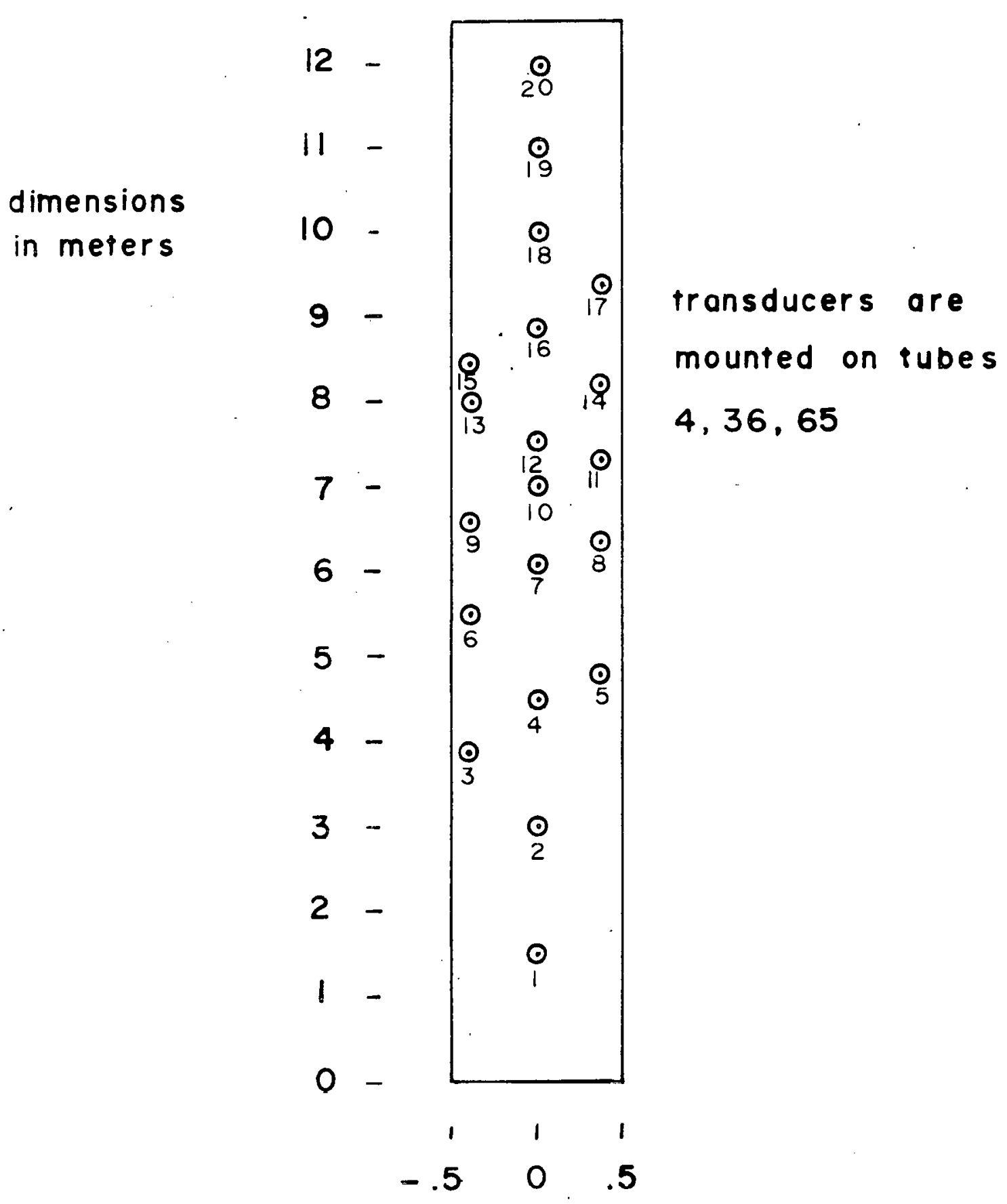


inches of spun saphire insulation were placed over the back of the receiver with two-foot stainless steel coaxial cables on the transducers sticking through it. A $3 . \mathrm{M}$ length of $\mathrm{RG}-196 / \mathrm{U}$ cable took the signal the rest of the way from the transducer to the preamplifier. The use of microdot connectors at the stainless steel-teflon cable junction eliminated any soft solder joints in the signal path before the Input to the preamplitier. The preamplifiers were Acoustic Emission I'echnology $140 \mathrm{~A}$ 's with $40 \mathrm{db}$ gains and $12.5-250 \mathrm{kHz}$ hand pass filtero. These preamplifiers survived a year of exposure to extreme heat and cold and other abusive treatment including several being filled with water.

The data acquisition system was an AET acoustic emission source location system. This system measured the signal level at each transducer and then recorded the data set on digital magnetic tape. All data was taken at a sampling rate of 10 data sets per second. A data set consisted of the signal levels of the twenty transducere and the time at which the set was taken. An experimental run consisted of about 3000 data sets taken over a five minute period. The experimental runs were made after the receiver had appeared to have reached a steany state for a given set of operating conditions.

The averaging time during the signal level measurements was approximately $30 \mathrm{msec}$ and the total system gain was usually $94 \mathrm{db}$. The background noise level at this gain (the noise level with hot water flowing in the receiver but without the heliostats focused on it) was usually less than $10 \%$ of the signal level during operation. Occasionally, outside sources of noise such as air leaks in the solar flux gauge 
cooling system, would necessitate a gain change during that day's run. The gain was set to keep the background noise at a level low enough in relation to the signal level so that it would not have to be included in the data analysis calculations.

The diameter of the focal spot for most of the heliostats was on the order of two meters at the position of the receiver. As the receiver width was 0.9 meters, the full power could not be deposited on the receiver. To remedy this two sets of concentrating mirrors were installed along the edges of the receiver. With these mirrors, over $3 \mathrm{MW}$ of solar energy could be absorbed by the receiver. Unfortunately, the concentrators could not provide even illumination across the face of the receiver. The intensity at the center was greater than at the edges. On the last test, to allow the absorption of $3 \mathrm{MW}$ of power, orifices were pulled out of the center tubes, giving higher water flow rates in the center of the receiver.

During the tests of the receiver, the instrumentation at the Central Receiver Test Facility was used to record many parameters. These include the solar flux level, output steam temperatures, pressures and differential pressures in some of the tubes, water flow rate and the surface temperature on the receiver as measured by hundreds of thermocouples. All of this data was recorded at data acquisition rates of a sample every two seconds. Unfortunately no filters were used in any of these data channels to. prevent aliasing. As will be discussed later, this sample rate with the probable distortion by aliasing, does not allow much correlation between this data and the acoustic experiment. 


\section{Data Analysis}

This experiment was designed to measure enough data to enable the solution of an overdetermined set of equations, 20 equations in two unknowns. One reason for using this approach is that the acoustic signal is composed of a sum of acoustic pulses which appear randomly in time. This signal has an essentially white noise component riding on the top of a slowly varying signal. Thus, using only two equations to solve for two unknowns can lead to very wrong answers. Another reason is that if the transition zone is not a horizontal line as assumed in Equation 2, two equations in two unknowns again will give wrong results while the best solution to an overdetermined set of equations will give an average vertical position of the transition region.

The solution of the set of equations used a nonlinear least squares fitting program. This program was one of several available and when computer models showed that it worked, no others were tried. In these models, it proved capable of giving the correct answers to a set of equations similar to Equation 2 when $10 \%$ random noise was superimposed on the calculated inputs and drastically wrong initial guesses for the unknowns were used. In addition to calculating the best values for the unknowns, the program gives an estimate of how well the data set fits the equations.

One modification of Equation 2 was made to account for variations in the amplifier gains, transducer coupling efficiencies, and transducer sensitivities, both between channels and at different times. This modification was the introduction of the parameter $K_{i}$ in Equation 2 . 
The equation used in the data analysis. was

$$
A_{i}^{2}=A_{0}^{2} K_{i}^{2} \int_{-a}^{a} \int_{0}^{C} X(x) Y(y) e^{-2\left(\alpha^{2}\left(x-w_{i}\right)^{2}+\beta^{2}\left(y-V_{i}\right)^{2}\right)^{1 / 2}} d y d x
$$

The acoustic power distribution functions, $X(x)$ and $Y(y)$, were developed empirically to give a reasonable fit to the data. For the experiments before the concentrating mirrors were used, the flux density was essentielly constant over the horizontal dimension of the receiver since the focal spots were wider than the receiver. For this case I used the simple approximation, $X(x)=1.0$. With the concentrators in place, the horizontal flux density was quite nonuniform and this was complicated by the removal of the orifices in the central tubes. For this case, the best fit to the data was obtained with the function

$$
\mathrm{x}(\mathrm{x})=\left(1+(1.5 \mathrm{x})^{3}\right)
$$

For the vertical acoustic power distribtuion function I found reasonable fits to the data with the function

$$
Y(y)=1 / 2(1+\tanh (r(y-C / s)))
$$

where $r$ and $s$ are adjustable parameters. The function $\mathrm{Y}(\mathrm{y})$ is assumed to be zero above the point $C$ so that there is no contribution to $A_{i}$ from the region between $\mathrm{C}$ and the top of the receiver. The parameters $r$ and $\mathrm{s}$ lay in the ranges $0.1 \leq \mathrm{r} \leq 20.0$ and $1.5 \leq \mathrm{s} \leq 20.0$. Physicaliy, small values of $r$ correspond to the start of nucleate boiling at different levels in different tubes while a large value indicates that the boiling started at. a sharply defined vertical level on the receiver. A large value of $s$ would indicate that the region where nucleate boiling 
occurred extended a long way down the receiver f'rom point $c$. This occurred at the lower power levels as might be expected. The function $\mathrm{Y}(\mathrm{y})$ is shown for two different sets of experimental conditions in Figures 4 and 5 .

To solve the set of equations, Equation 3, the attenuation $\alpha, \beta$ and the gain-coupling coefficients, $K_{i}$, must be known. A calibration of the acoustic system was attempted by driving one transducer with a white noise signal and then recording the acoustic signal level at the other nineteen transducers. The following set of equations could then be solved.

$$
A_{i}=A_{0} G_{i} H_{i} H_{j} e^{-\left(\alpha^{2}\left(W_{i}-W_{j}\right)^{2}+\beta^{2}\left(V_{i}-V_{j}\right)^{2}\right)^{I / 2}}
$$

where the i's are the receiving transducers and the $j$ 's are the transmitting transducers. The $G_{i}$ are the preamplifier gains which could be measured and the $\mathrm{H}_{i}$ and $\mathrm{H}_{j}$ are the coupling-sensitivity coefficients. This procedure gave 400 equations in 23 unknowns, the $20 \mathrm{H}_{i}, \mathrm{~A}_{0}, \alpha$ and $\beta$. The problem that developed is that Equation 6 assumes the transducers are reciprocal; that is, that the acoustic generating and receiving characteristics are the same. Physical arguments can be made that the mounting method and the transducer design prevent these transducers from being reciprocal devices and the results of this calibration procedure suggested that this was the case. While 400 equations are more than enough to solve for the 63 unknowns, if we include the gains and the premise that $\mathrm{H}_{i} \neq \mathrm{H}_{j}$. when $i=j$, the nonlinear least square fitting program that I was using would not handle more than 25 unknowns. I 
FIGURE 4 - THE ACOUSTIC POWER DISTRIBUTION FUNCTION $\mathrm{Y}(\mathrm{y})$ WITH $r=20.0 \mathrm{AND} s=20.0$

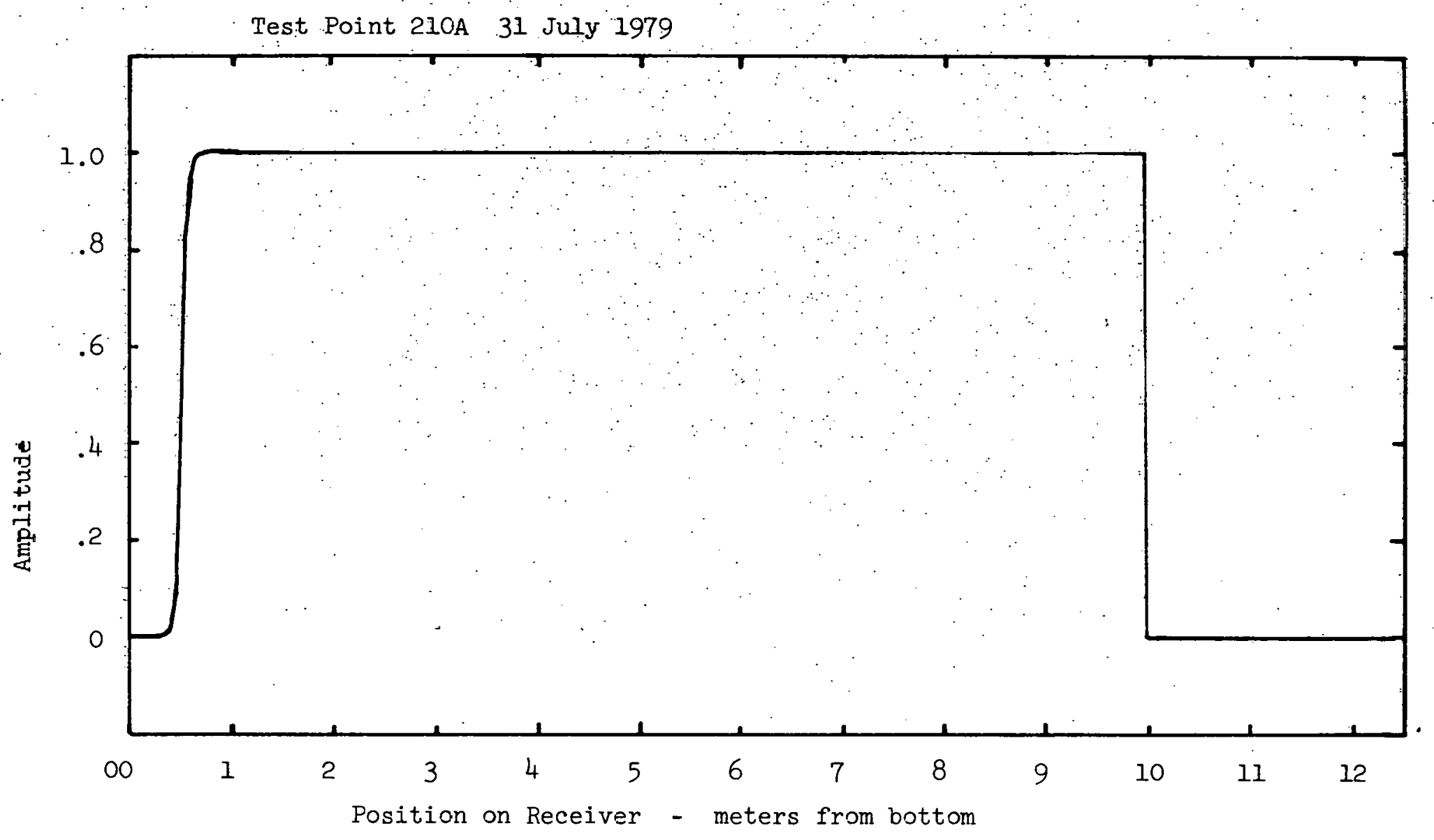


TEST POINT LIOF

$5 \operatorname{man} 1980$

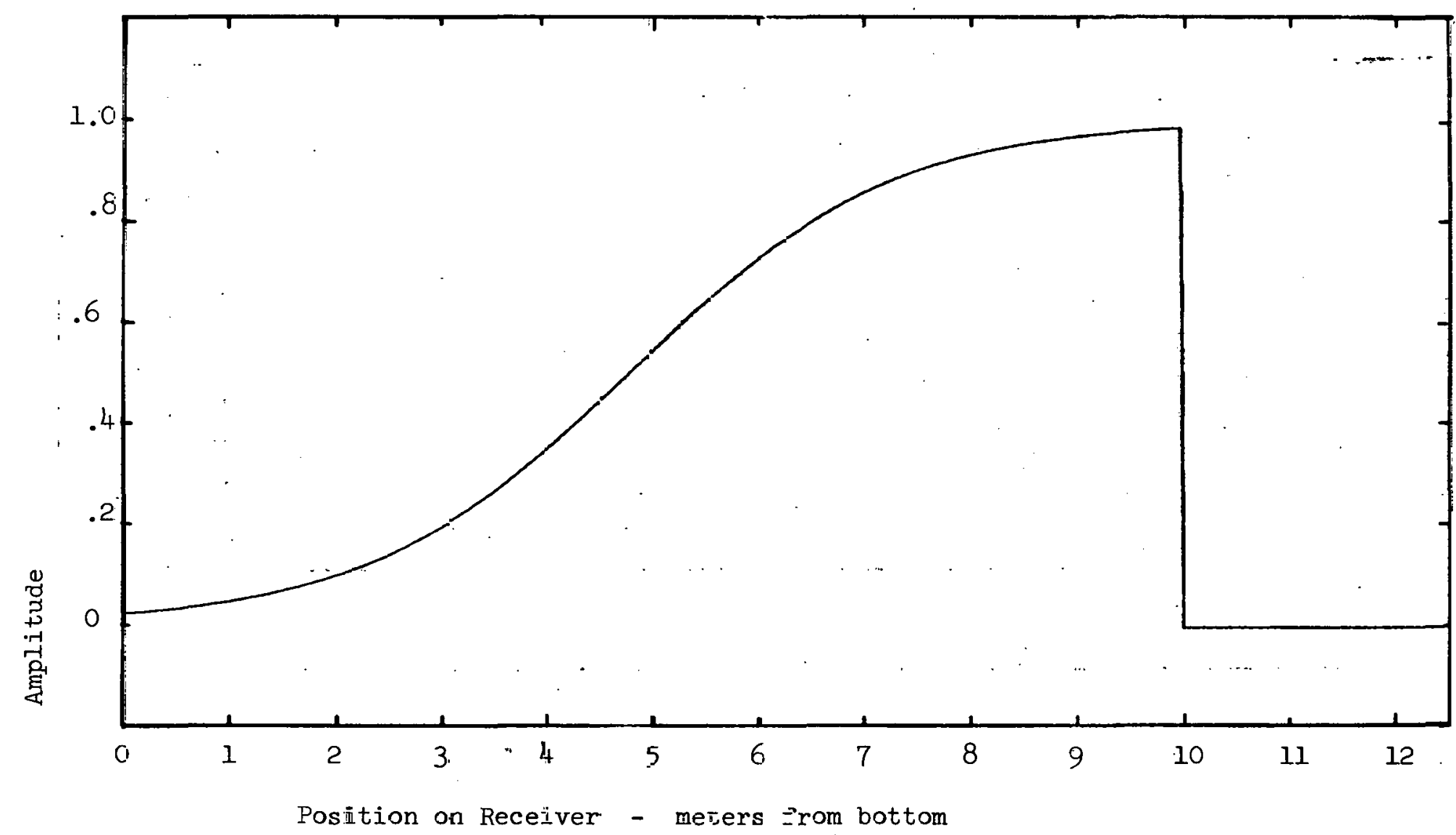


decided that probable changes in both the $\mathrm{H}_{j}$; the $\mathrm{H}_{i}$ and the $\mathrm{G}_{i}$ from day 0 day made this method of calibration not worth the effort to rewrite the fitting program for more unknowns. The only results retained from this calculation were the acoustic attenuation coefficients, $\alpha=2.0 \mathrm{~m}^{-1}$ and $\beta=0.27 \mathrm{~m}^{-1}$. Independent attempts to measure $\alpha$ and $\beta$ gave values within a factor of 2 of these results. All attempts to measure $\alpha$ and $\beta$ showed that $\alpha$ was approximately an order of magnitude larger than $\beta$, thereby confirming the assumption of an anisotropic attenuation in the receiver.

Instead of measuring the gains and coupling coefficients, they were lumped together into gain-coupling coefficients, $K_{i}=G_{i} H_{i}$, which had to be determined from the data. To do this, the following assumptions were made. First, that the gain-coupling coefficient, $\mathrm{K}_{i}$, would remain constant throughout one day"s experiments. Second, that the acoustic power distribution functions would not change during that day's experiments and third, that the attenuations were independent of temperature: Using these assumptions, the following procedure was used to analyze the data.

Hirst, the raw data sets from all the experimental runs for one day were examined. For each run, ten consecutive data sets (one second of running time) were selected from an apparently calm period. The ten readings from each transducer were averaged. The averaged data set from what was thought to be the most typical of the day's runs was selected. The set of equations, Equation 3, was then solved for the data set with the $\mathrm{K}_{i}=1.0$. The values of $r$ and $s$ in Equation 5 were varied until the best fit was obtained. These values of $r$ and $s$ were then used to 
calculate the values of $C$ and $A_{0}$ for the averaged data set from each experimental run. For each run, the calculated values of: $C$ and $A_{0}$ were put back into the equations, Equation 3 , and the values of $A_{i}$ for each transducer were calculated, still with $K_{i}=1.0$. A set of $K_{i}$ were then defined for each experimental run for the day from the equation

$$
K_{i}=A_{i}(\text { experimental }) / A_{i}(\text { calculated }) .
$$

The $\mathrm{K}_{\mathrm{i}}$ for each transducer were averaged over the experimental runs for that day and this final set of $K_{i}$ along with the values of $r$ and $s$, were used to analyze all the data collected on that day: It should be stated that this rather laborious procedure was made feasible by the ability to make the calculations in a reasonable time on a time-sharing computer terminal.

After $r, s$ and the $K_{i}$ were determined, the first 2500 data sets collected as an experimental run were solved for $A_{0}$ and $C$. This calculation was done on a CDC 7600. Because of the numerical integrations required in the solution of Equation 3, the solution of each data set took between 0.75 and 1.0 seconds of computer time. Figure 6 is a plot of these solutions for $\mathrm{C}$ as a function of time. Spectral analysis of this type of raw output from the calculation showed that few of the spectral components with periods shorter than two seconds contained appreciable amounts of energy. Therefore, several smoothing techniques could be used to make the data more usable without distorting the information containcd.

To smooth this output, firstall points were removed where the least squares program indicated a very poor fit to the data. Nineteen 
IHE CALCULATED POSITION OF JUE TRANSTIION ZONE LOCUS AS A FURCION OF E. THE UISMCOTIED CURVE FOR FU. $410 \mathrm{~F}$.

$410 \mathrm{~F}$

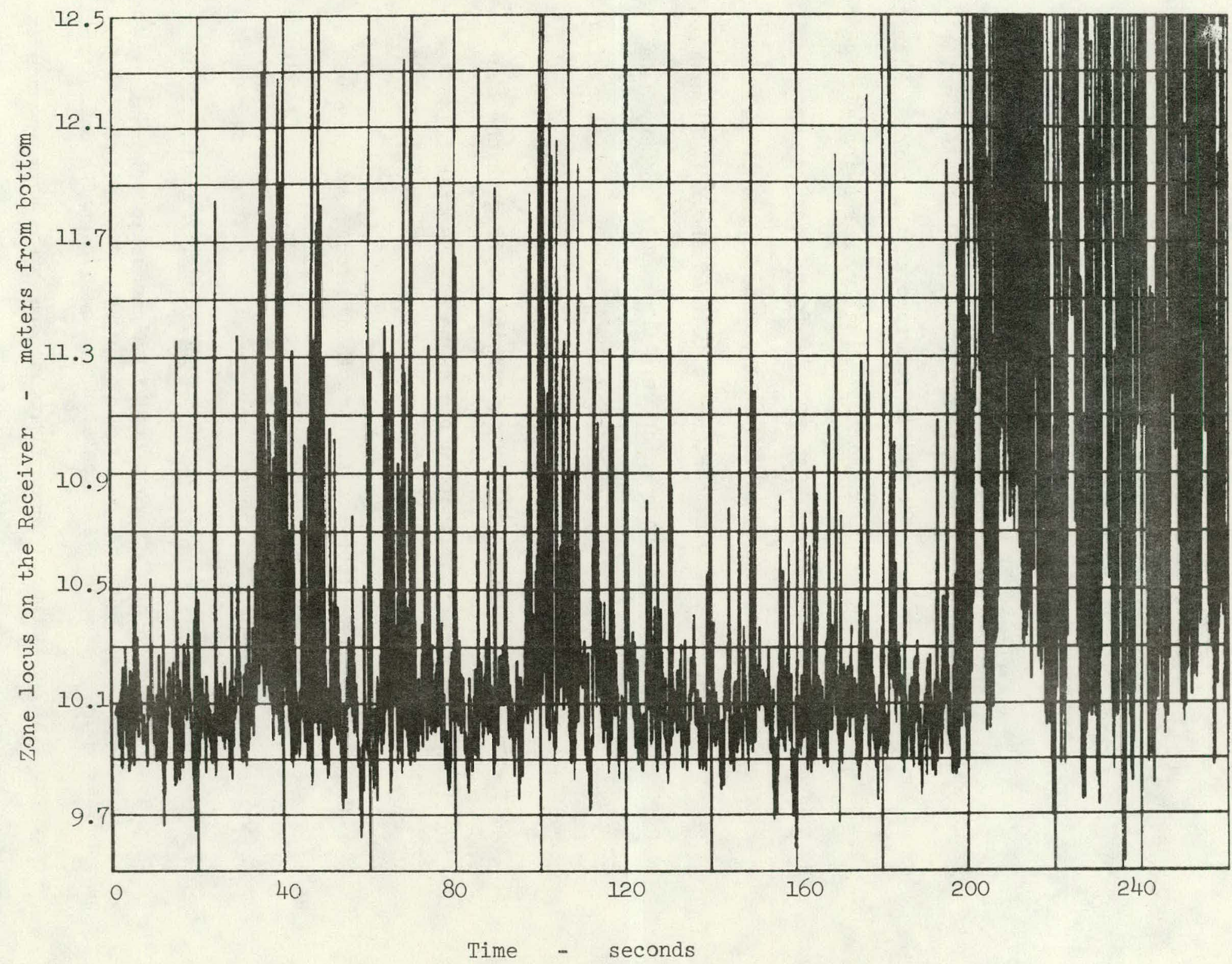


points were removed from Figure 6 for this reason. Second, examination of the outputs of many runs showed that there were usually 50 to 100 points which were much higher or lower than the adjacent points. To remove these isolated points, a running average was taken of the five preceding points. If the point differed by more than $10 \%$ from this average, it was replaced by a value which was $5 \%$ higher or lower than this average. This procedure still allowed rapid changes in the position of the curves formed by the points but removed the points which had no relationship to the preceding points. Finally, a running average of nine points, the point for that time and the four preceding and following points, was substituted for that point. These procedures changed the presentation shown in Figure 6 to that shown in Figure ' As can be seen, large excursions which were the result of many data points were not effected by the smoothing procedure but the obscuring grass was removed. Many variations of these procedures were tried on dif't'erent experimental runs. 'I'he ones described here gave the best smoothing with the minimum effect on the shape of the transition zone locus versus time curves.

In addition to the effect of the smoothing procedure there was a major question as to how model dependent these curves were. Calculations were made on the same experimental run with different values of the parameters $r$ and $s$, changes in the attenuations, $\alpha$ and $\beta$, of up to $\pm 50 \%$ and the effect of different horizontal acoustic power distribution functions, $X(x)$. These calculations showed that the calculated average vertical position of the transition zone could vary as much as a meter with different values of these parameters but that the shapes 
of the locus versus time curves appeared to be independent of the paramets values. The peak to peak amplitudes, frequency content and fine structure in general, were almost totally independent of moderate changes in the values of the fitting parameters.

Once the smoothed'versions of the transition zone locus as a function of time curves were calcuated we could determine the amplitude and frequencies of the movements of the transition zone. Computer programs were written to measure the peak to peak amplitudes of the curves and also to measure their spectral composition. The peak to peak amplitudes of the faster fluctuations in position were the data of interest so the computer program ignored periods longer than 15 seconds. Periods longer than this can easily be read directly from the curves. Figure 8 is a plot of the peak to peak amplitudes of the fluctuations as a function of time for the curve presented in Figure 7 . The Fast Fourier Transform of Figure 7 was also calculated and the amplitude of the frequency components determined. Figure 9 is a graph of these amplitudes plotted as a function of the period, instead of the frequency. Again both of these programs were checked by going back to magnified plots of the original curves and directly measuring the peak to peak amplitudes and estimating the frequency components present.

\section{Results and Discussion}

This experimental measurement is based upon a rather simple physical model of acoustic noise produced by nucleate boiling. If the model is wrong or incomplete, then resulting measurements may be meaningless. In addition to the physical model, the measurement also relies on a long series of mathematical calculations and manipulations. 


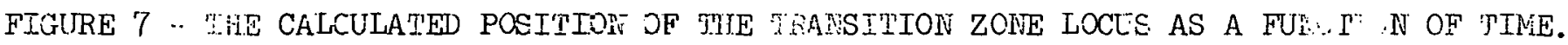
3HOOTHEI CURVE FOF RUT HIOF.

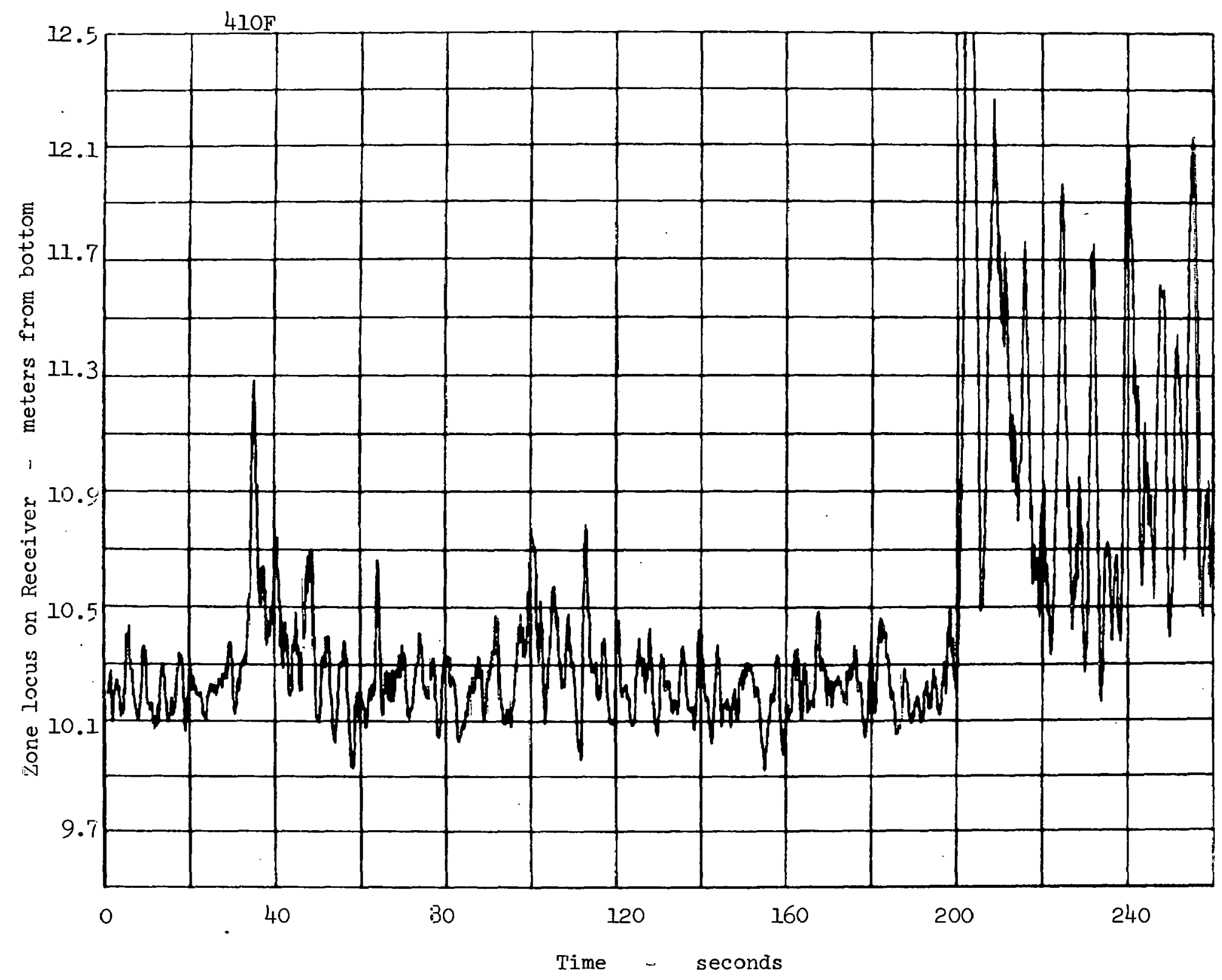


FIGURE \& - THE PEAK TO PEAK AMPLITU⿴囗十 OF THE FLUCTUATIONS IN THE TRANSITION ZOAE LOCUS AS A FUINCTION CF TIME. RUN 4 LOF.

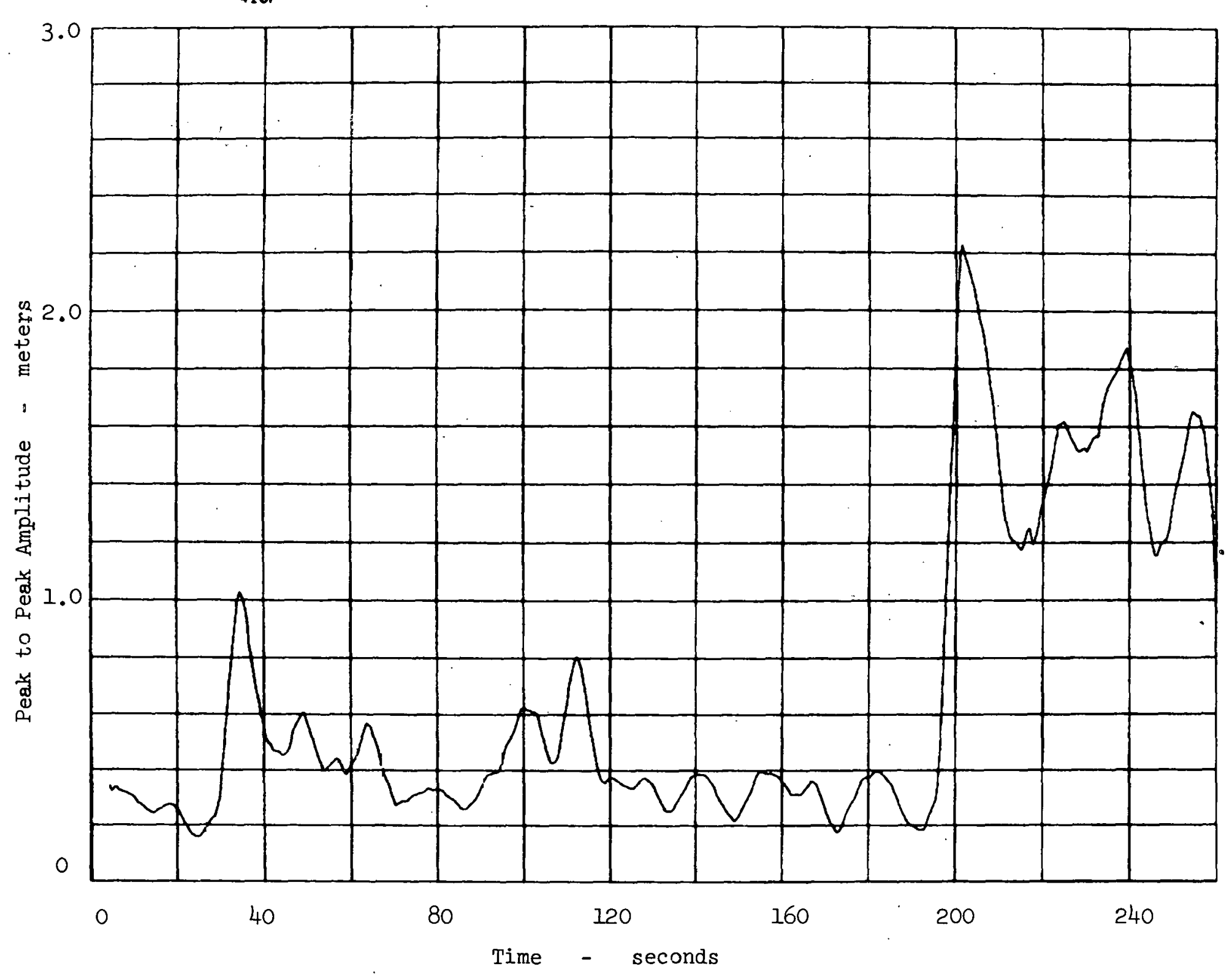


FIGUFE 9 - SPETTAL AMPLITDES OF IILE TRANSITION ZOITE FLUCIJAIICHS FOR RUI: 4IOF PLOTIED AS A FUIYTION OF THE PERIOD DF THE FLUCTUATIOHS.

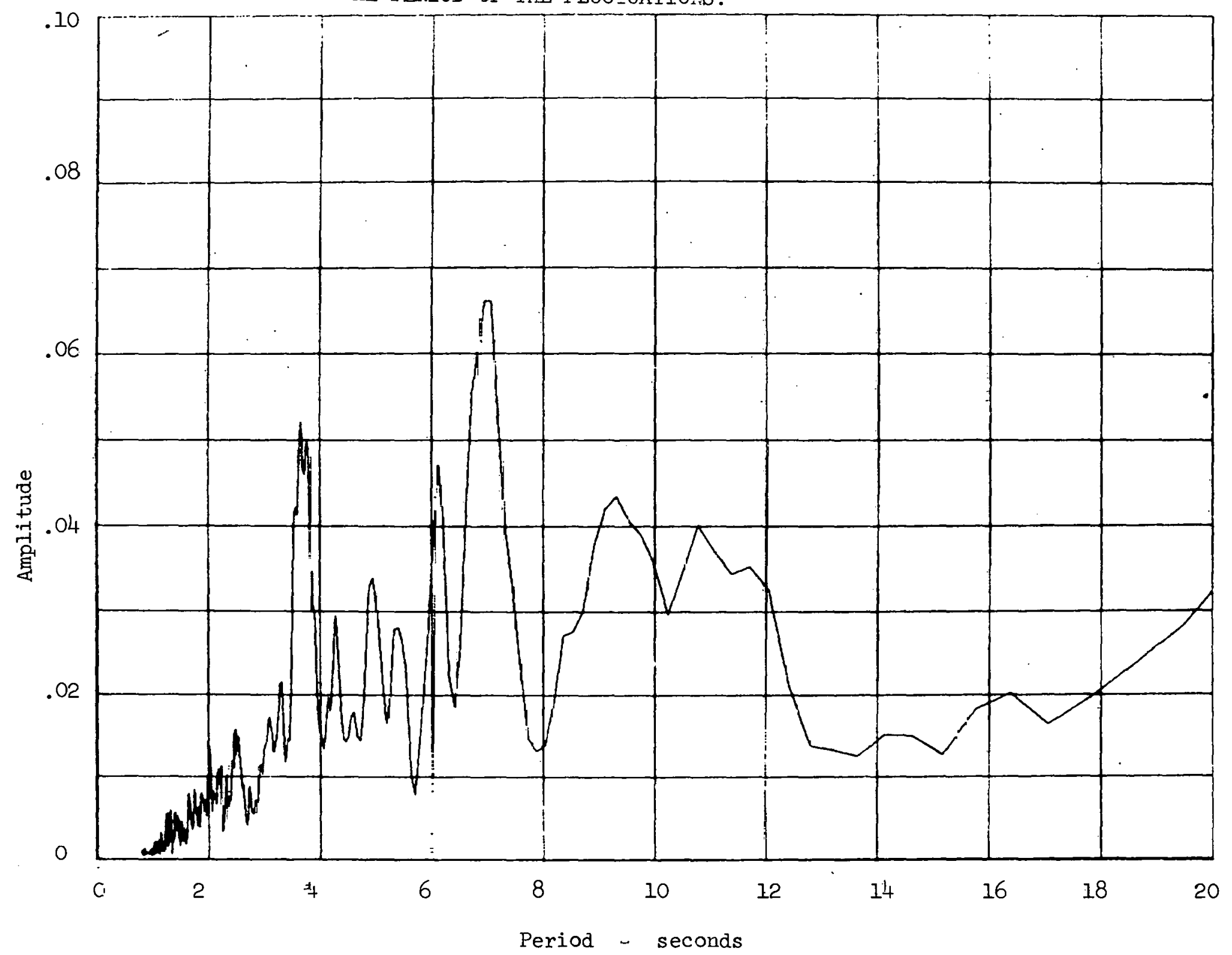


These also have the capability of distorting the measurement. To make a judgment on the validity of the measurement one must compare the final output with other independent measurements on the receiver. Figure 10 shows a curve plotting the locus of the transition zone as a function of time for one of the early experimental runs. On this run, CRTF personnel reported wet steam coming from the receiver, indicating that the transition region had reached the top of the receiver. This is in agreement with the measured position of the locus shown in Figure 10. In the experimental run shown in Figure 11, the receiver controller was oscillating with a period of about 48 seconds, moving the control valve to produce an oscillation in the feed water flow. Figure Il shows both the transition zone position and the flow. Note that the oscillations are in phase and that the transition zone moves up the receiver with . increased flow. Thus, the transition zone again moves as expected. It should be noted that the acoustic data and the water flow were recorded by completely independent data acquisition systems. The conclusion drawn from Figures 10 and 11 as well as from the other 40 experimental runs analyzed is that this acoustic measurement is locating the position of the transition region and measuring its movement in time.

Another que stion that needs to be addressed is whether the transition region fluctuates independently in each tube or whether the regions in most of the tubes move together so that there is a transition zone defined for the whole receiver. The experiment was designed with ten transducers mounted on one of the center tubes and five transducers each on two outer tubes. The transition zone locus for the experimental run shown in Figure 7 wa recalculated uøing the data from only the ten 
FIGURE 10 - TRANSITION ZONE POSITION AS A FUNCTION OF TIME FOR RUN 3.2A

TEST POINT 3.2-A

8 MAY 1979

ZERO SECONDS STARTS AT 12:17:40 HOURS

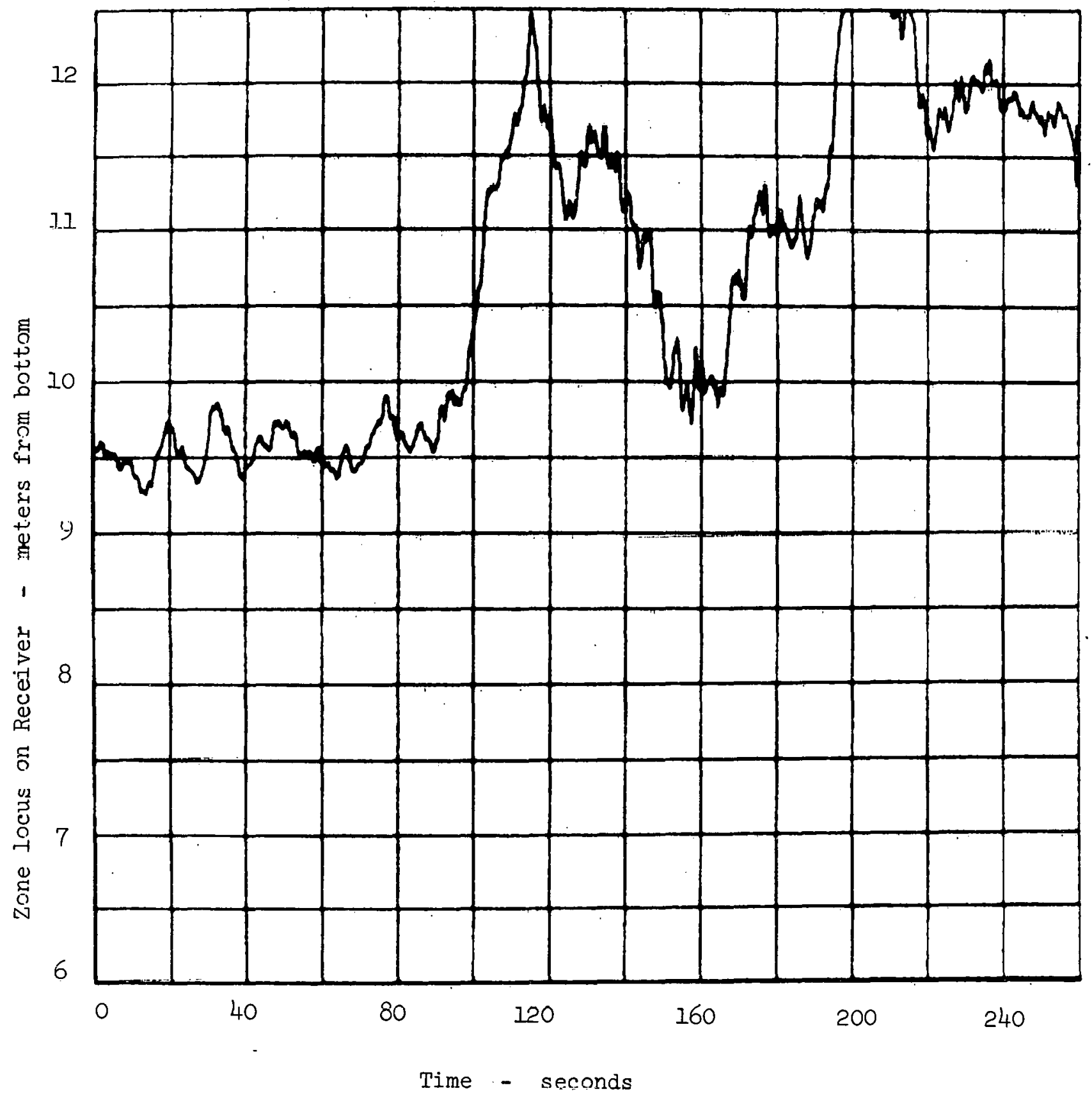


FIGURE 11 - TRANSITION ZONE POSITION AND FEED WATER FLOW AS A FUNCTION OF TIME FOR RUN 208A

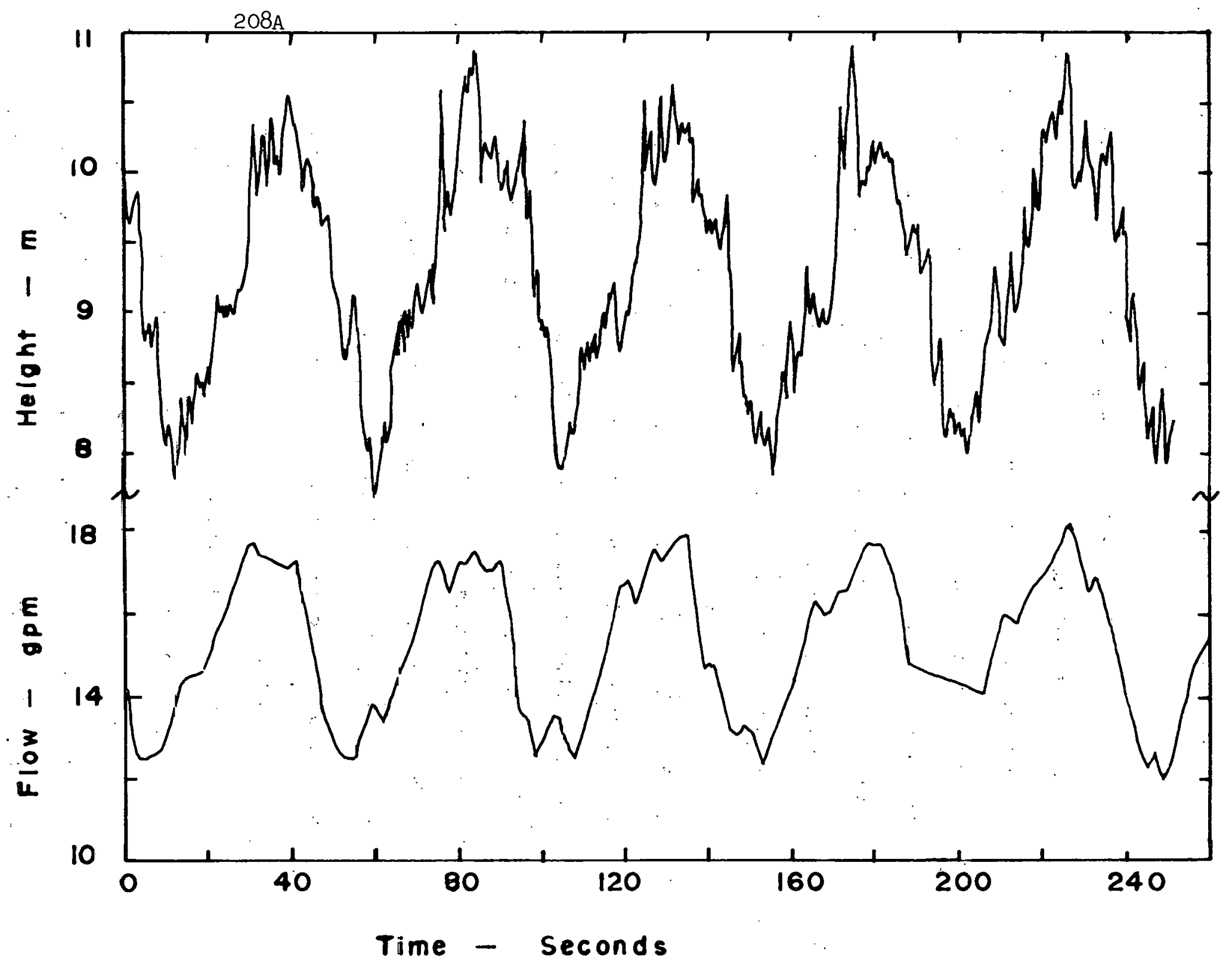


transducers in the center. This result is shown in Figure 12. If the transition regions in each tube were moving independently, one would expect the curves in Figures 7 and 12 to be quite different, especially since the high horizontal attenuation tẹnds to deçouple the signals measured by these three sets of transducers. Instead we see that Figures 7 and 12 are very similar which is strong evidence that the individual transition regions in each tube move in phase with the others and that the calculated position is indeed the locus of the average vertical position of a transition zone extending across the whole receiver. Again this calculation was made for some ten other experimental runs taken at different times during the testing of the receiver and the same conclusion was reached for each run.

Figures 13 and 14 show the transition zone locus for two more experimental runs taken during the final day of high power testing. The relationship in time between Figures $7, .13$ and 14 are shown in Figure 15. During this time span, the average absorbed power in the receiver was $3.0 \mathrm{MN}$ with: a variation due to high clouds between 2.8 and $3.2 \mathrm{MW}$. Diring this period, the receiver was under manual, not automatic, control. Figures 16 and 17 show the peak to peak amplitudes of the fluctuations corresponding to Figures 13 and 14 . The conclusion from examining Figures 8,16 and 17 and similar results from other experimental runs is that there is a background fluctuation during steady state operation of about 0.4 meter peak to peak amplitude. This amplitude appears reasonably constant for absorbed powers of 2 MW or more, dropping somewhat at lower power levels. At random times during this steady state operation, large fluctuations would occur such 
FIGURE 12 - TRANSITION ZONE POSITION AS A.FUNCTION OF TIME FOR RUN 410F. THIS CURVE WAS CAL_ULATED

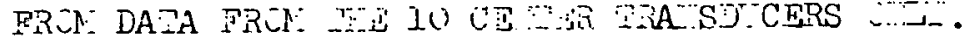

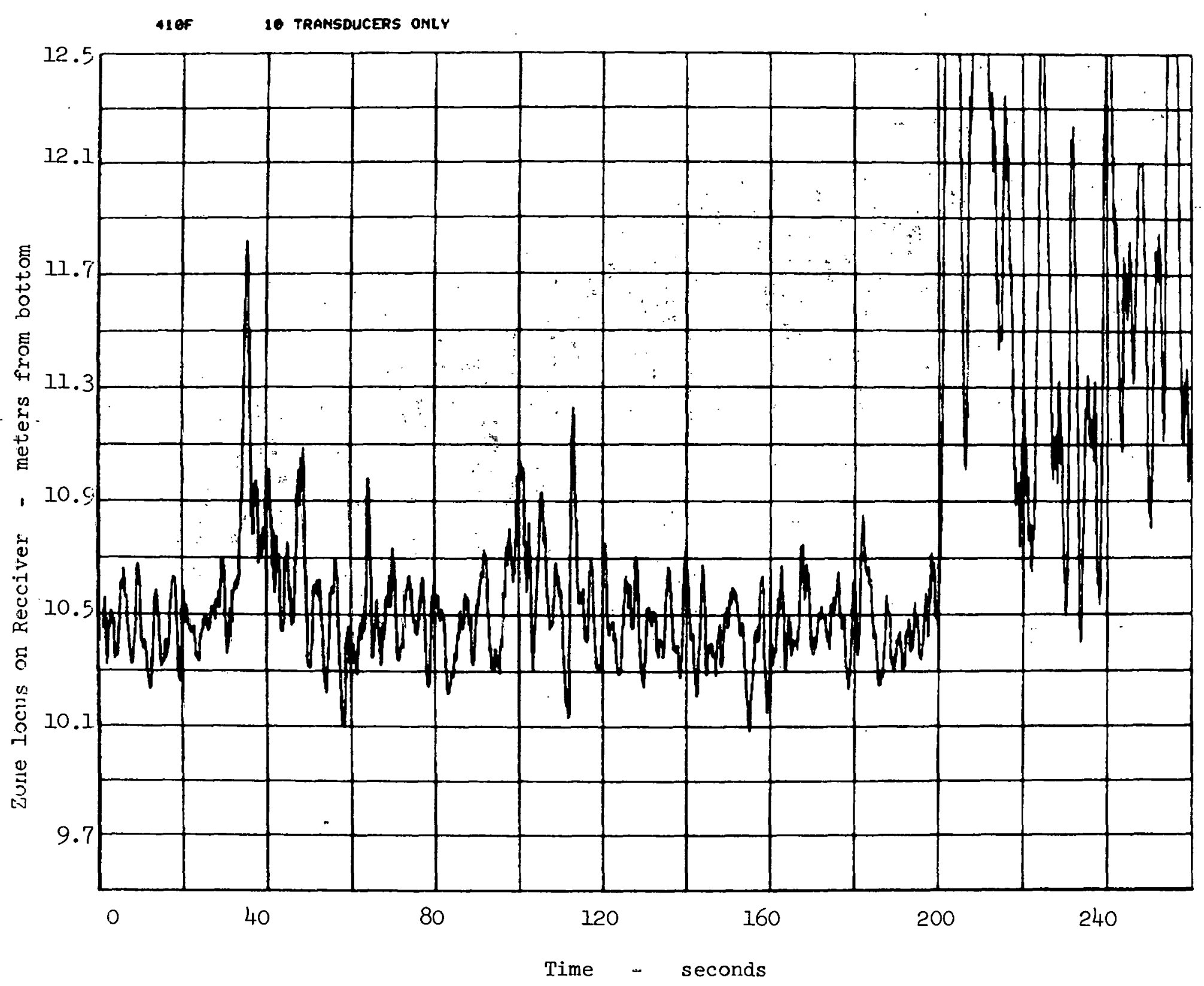




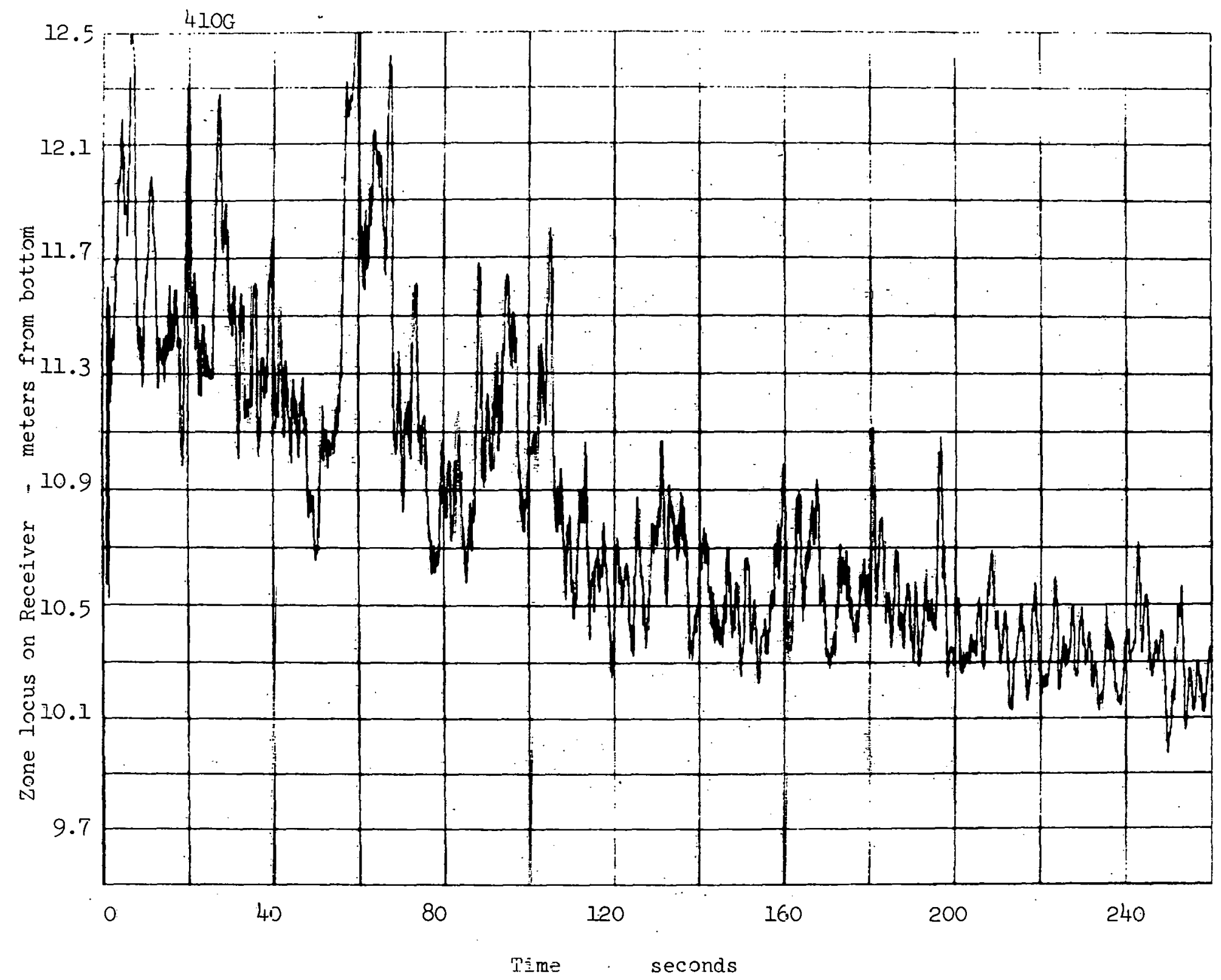




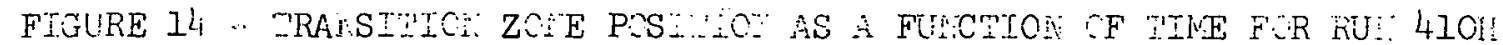

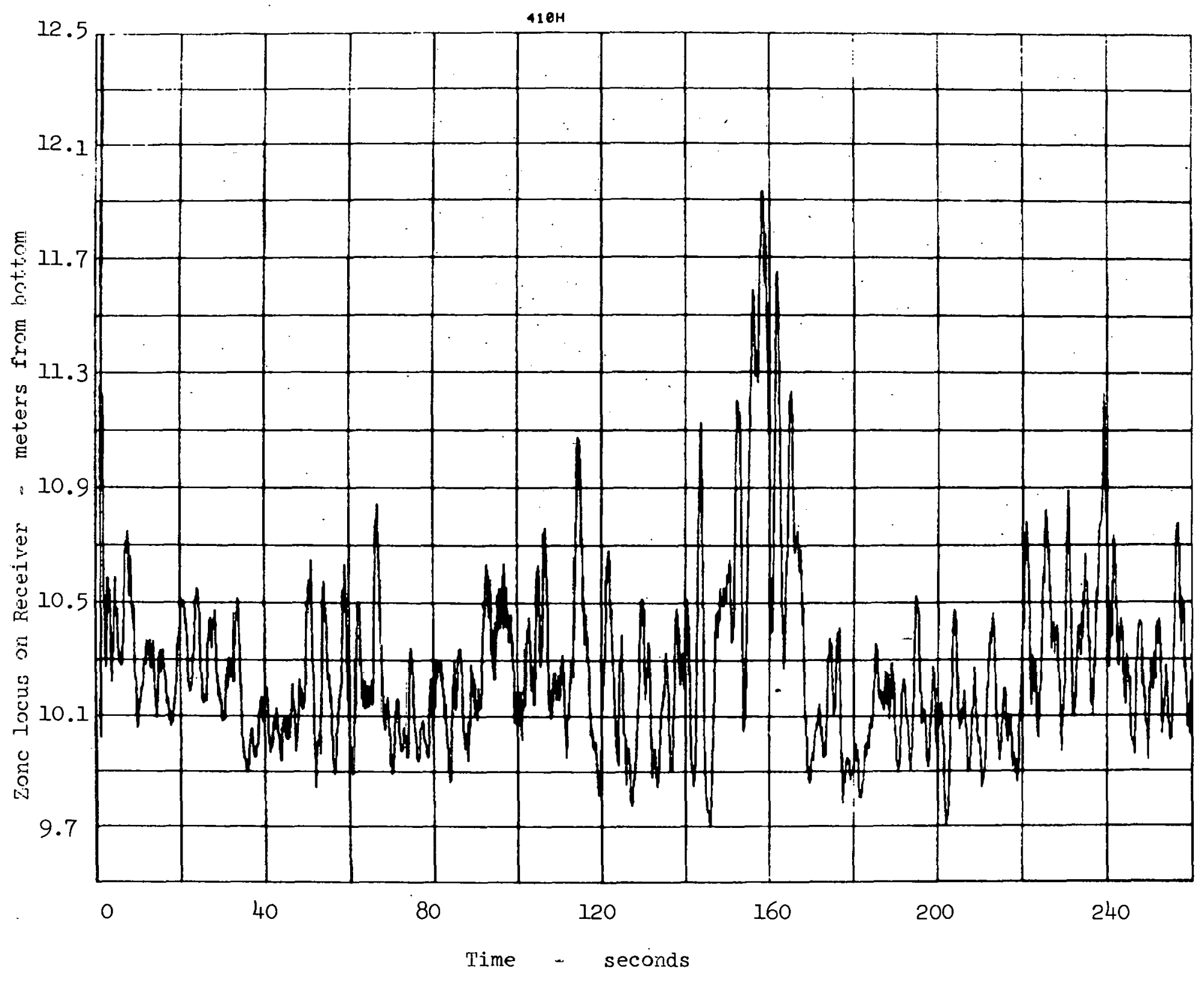




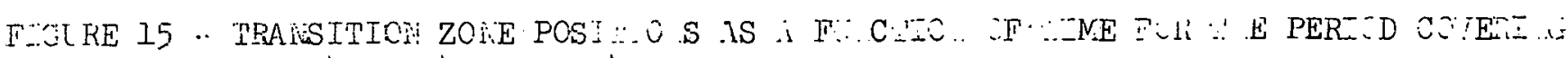
RUNS 4IOF, 410G anc 410 :

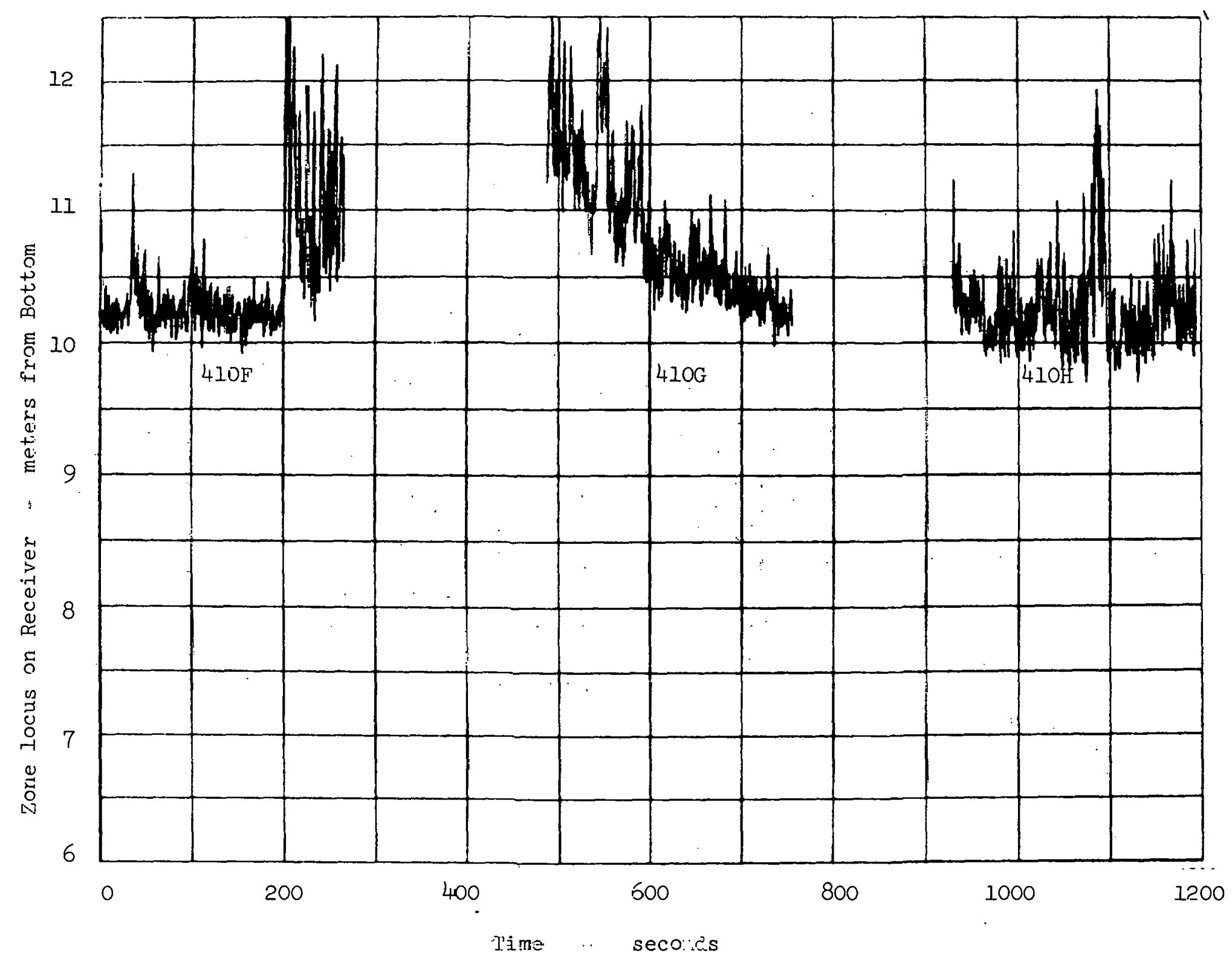


FIGURE 16́ -. THE PEAK TO PEAK AMPLTUDES OF TPE FLUUCTUATOIS FOR RUI: $410 G$

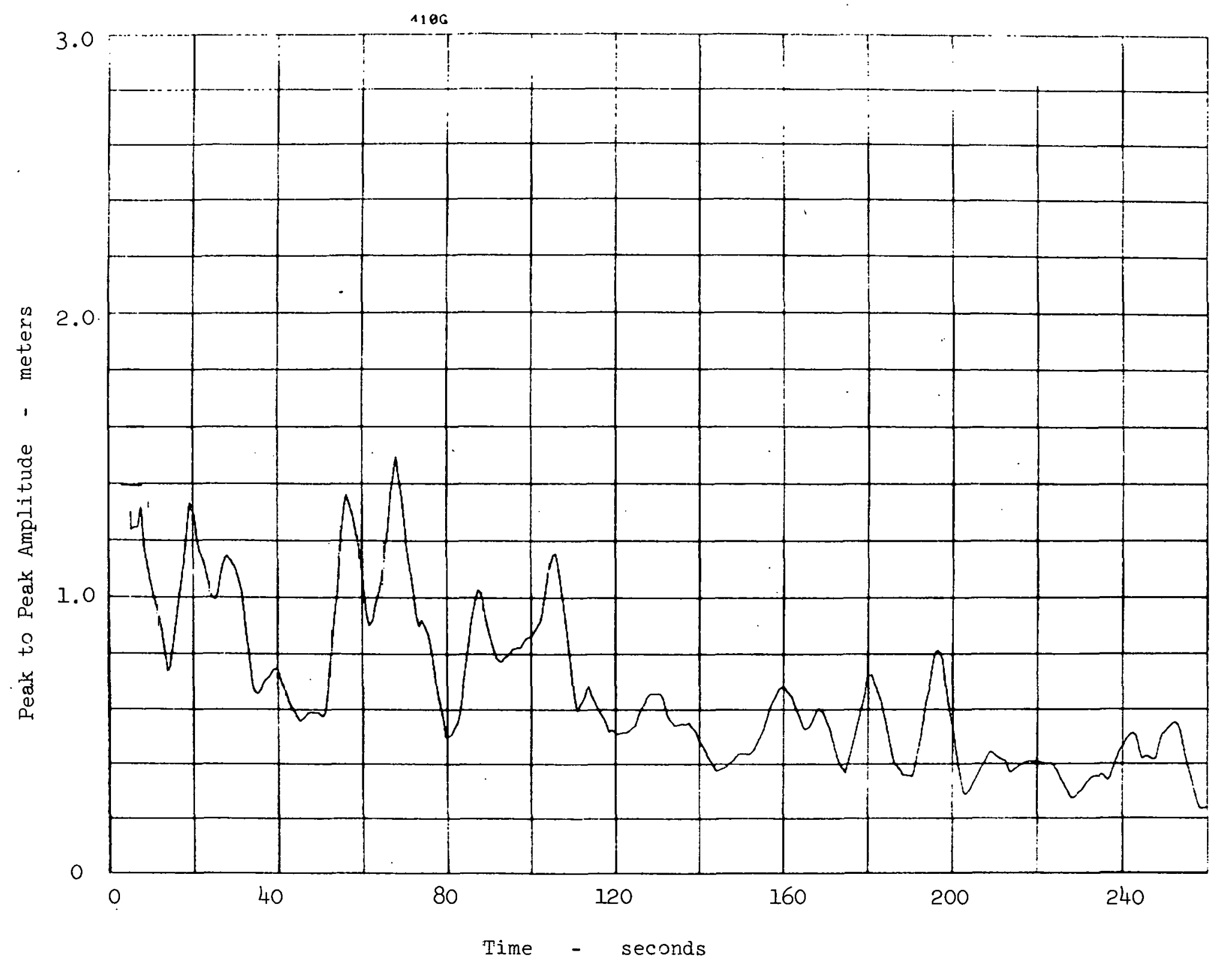




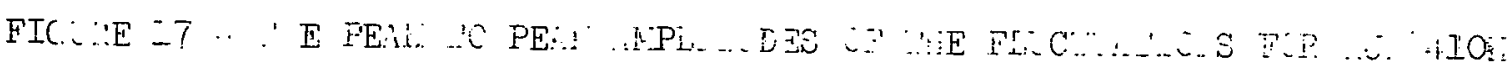

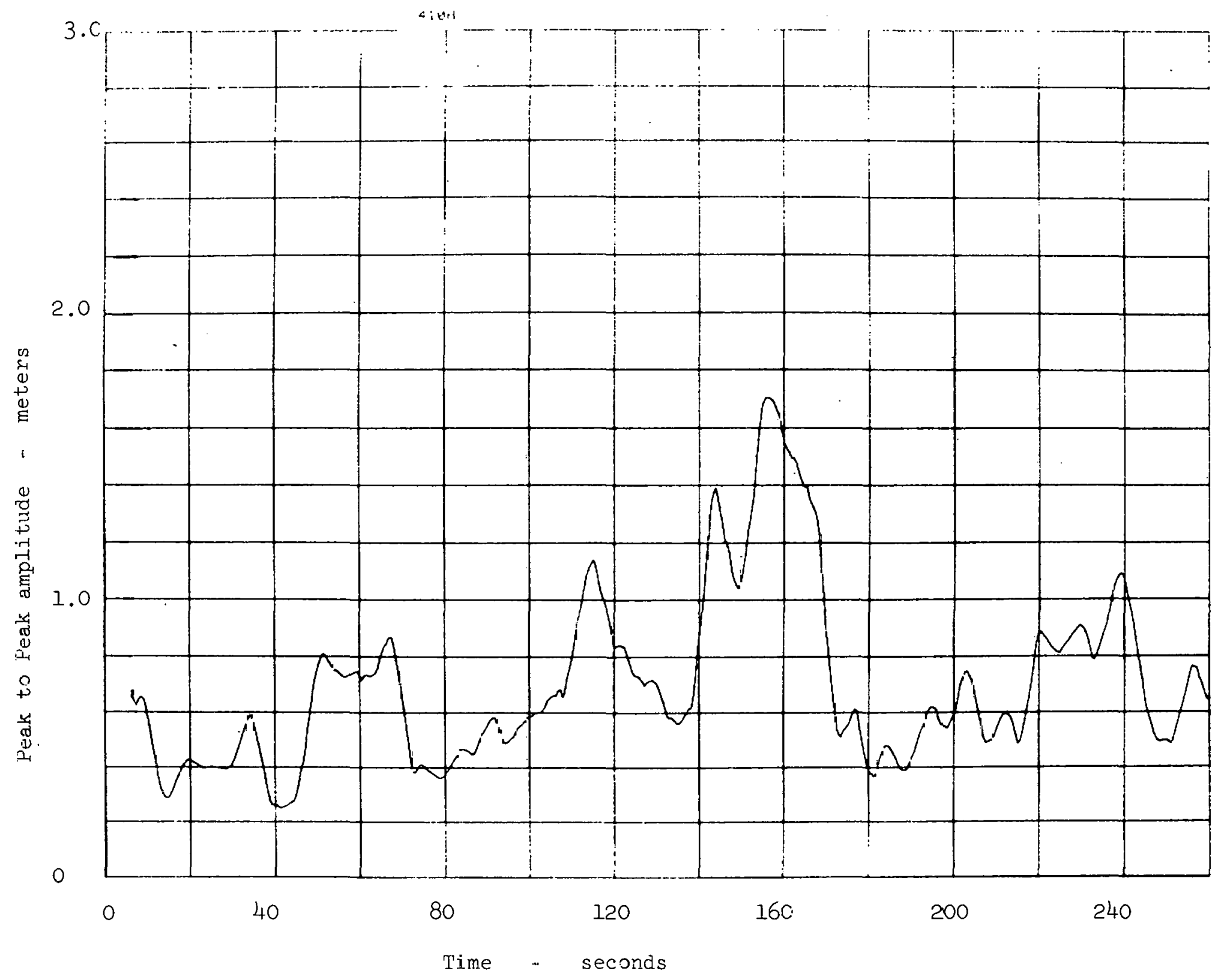


as those starting at 35 and 200 seconds in Figure 7 . These large fluctuations appeared to last for periods of time between 30 and 300 seconds and can have peak to peak amplitudes as high as 2.0 meters. In addition, controller oscillations, such as those shown in Figure 11, could produce fluctuations riding on top of the oscillation with amplitudes around 0.8 to 1.0 meters. In general, the outbreak of large amplitude fluctuations such as those seen at 200 seconds in Figure 7, cannot be correlated with other data recorded at the CRTF. However, these particular fluctuations seen in Figure 7 occurred just as the steam temperature in several tubes in the receiver started to rise. These steam temperatures are shown in Figure 18. The cause of this steam temperature rise is, unfortunately, not known. In Figure 19, the steam pressure at the top of the receiver, the water flow through the receiver and the reading of the Epply pyroheliometer are all plotted and none show any significant changes which might have produced the fluctuations.

The start of the temperature increase corresponds exactly with the start of the fluctuations but there seems to be no reason for either in the rest of the data. One guess as to the cause of these effects lies in the control of the heliostats. While the heliostats are designed to automatically track the sun, the heliostat controllers in use at the time of this experiment were digital with a rather small control word. $\Lambda$ one bit change corresponded to a movement of the focal spot of six inches on the receiver face. While this movement would have little effect on the flux distribution on the receiver normally, the presence of the concentrating mirrors on the receiver edges could have 
FIGURE 18 - RECEIVER OUTPUT STEAN TENPERATURES IN TUBES 1, 40, AND 66 FOR RUN 4IOF

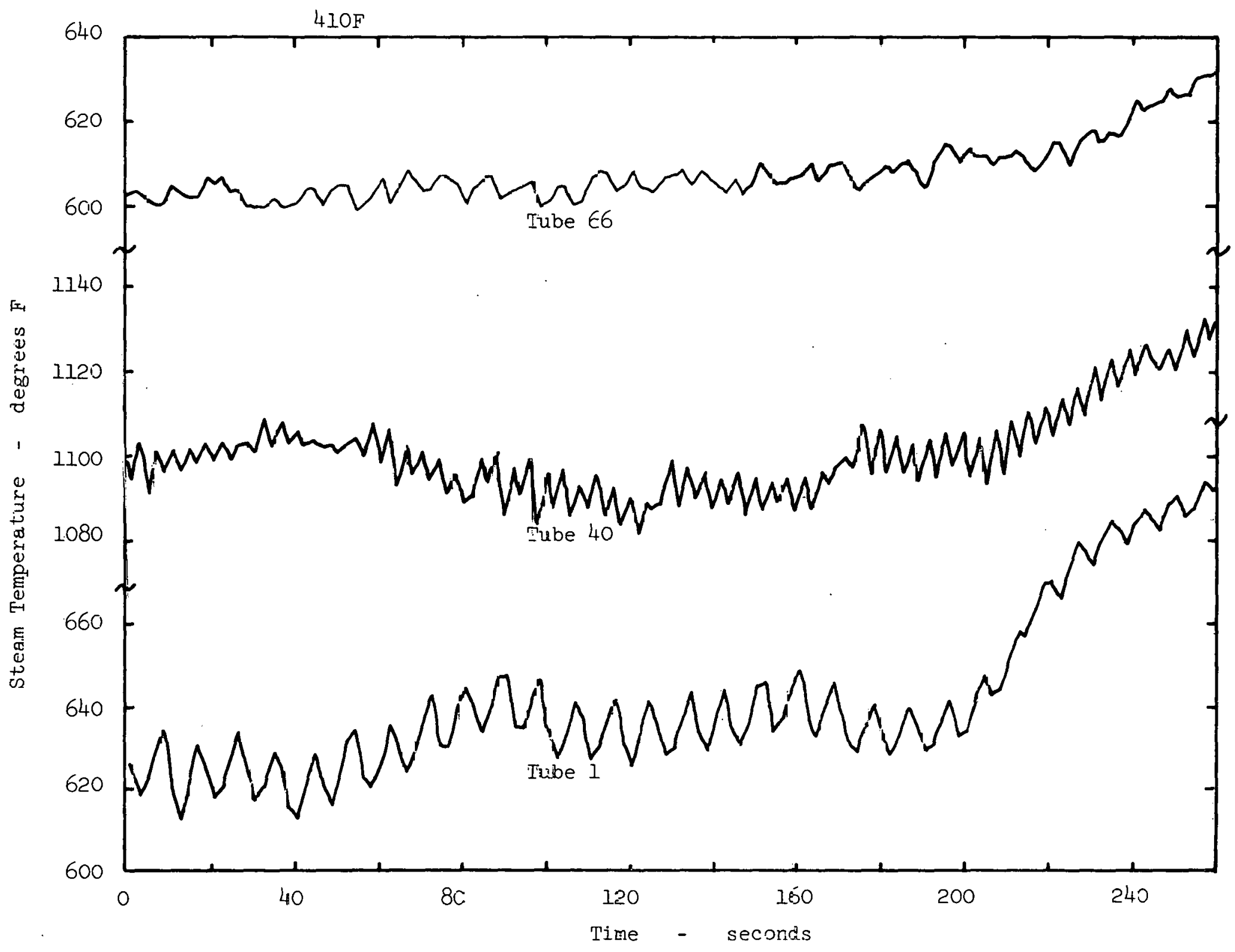



FIGURE 19 - OJTPUT STEAM PRESSURE, FEED WATER FLOW AND SOLAR FLUX MEASURED BY AN EPPLY
PIROHELIOMETER FOR RUN 4IOF

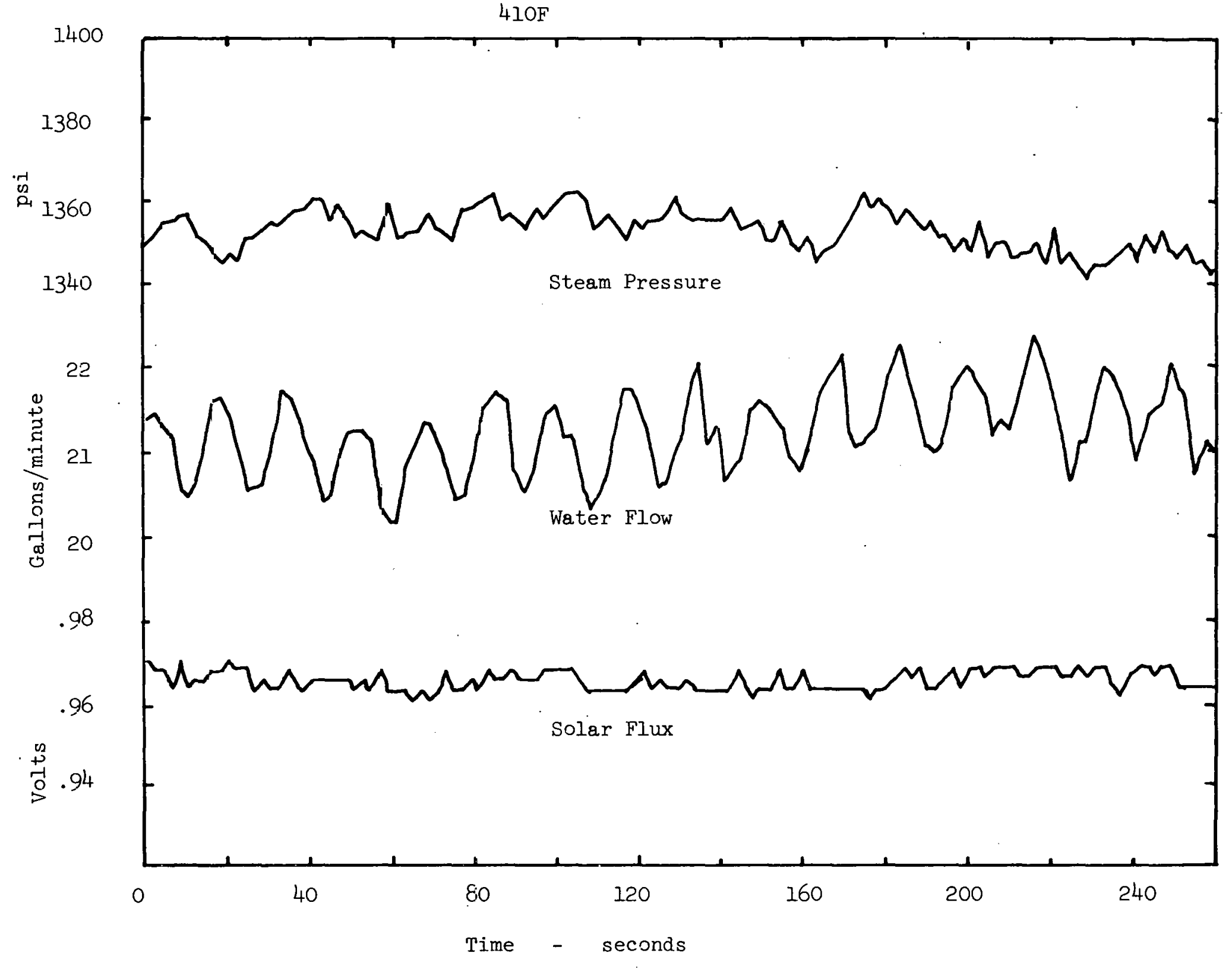


led to a large redistribution of incident flux with the six-inch shift of many heliostats. Unfortunately, measurements of the flux distribution on the receiver face were updated far too slowly to catch this sort of transient change. Thus, there is no data to prove that this actually happened.

The frequency components for the curves shown in Figures 13 and 14 are plotted in Figures 20 and 21 as a function of period. The large amplitudes around 15 to 17 seconds correspond to the low amplitude oscillation in the water flow seen in Figure 19. Comparing Figures 9, 20 and 21 , we see a number of high amplitude components with periods between 3 and 10 seconds. However, if we average the spectral intensities for all the experimental runs taken on the day when Figures 9, 20 and 21 were taken, we can see in Figure 22 that no spectral component dominates. Instead there is a broad plateau above the background from periods of about 3.5 seconds up to the flow oscillation period near 16 seconds. This strongly suggests that the receiver does not have a resonant frequency but that the periods of any given set of fluctuations in the transition zone position depend in a large part on the details of the stimulus that produced them. However, most of the fluctuations do appear to have periods between 3 and 15 seconds.

Attempts to correlate the fluctuation periods with frequencies seen in other data taken by the CRTF facility such as that seen in Figures 18 and 19, proved futile. The problem is that the CRTF data was digitized at a rate of a sample every two seconds. Sampling theory shows that at this sampling rate, frequency components with periods shorter than 4 seconds will be aliased and will appear to have periods 


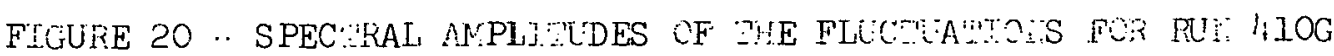

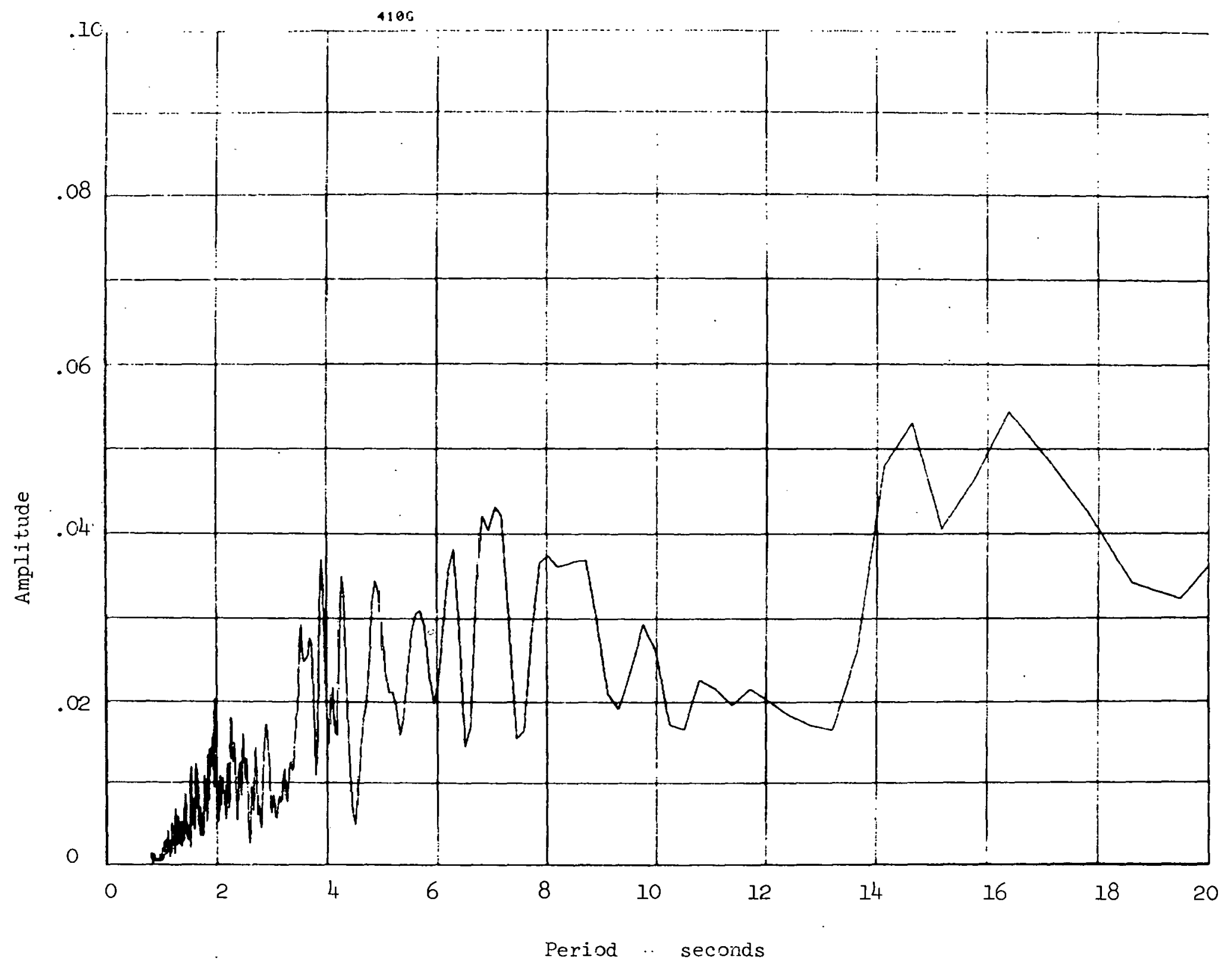




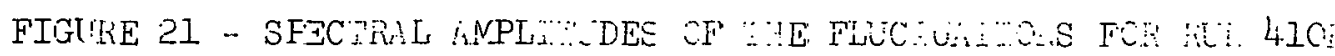

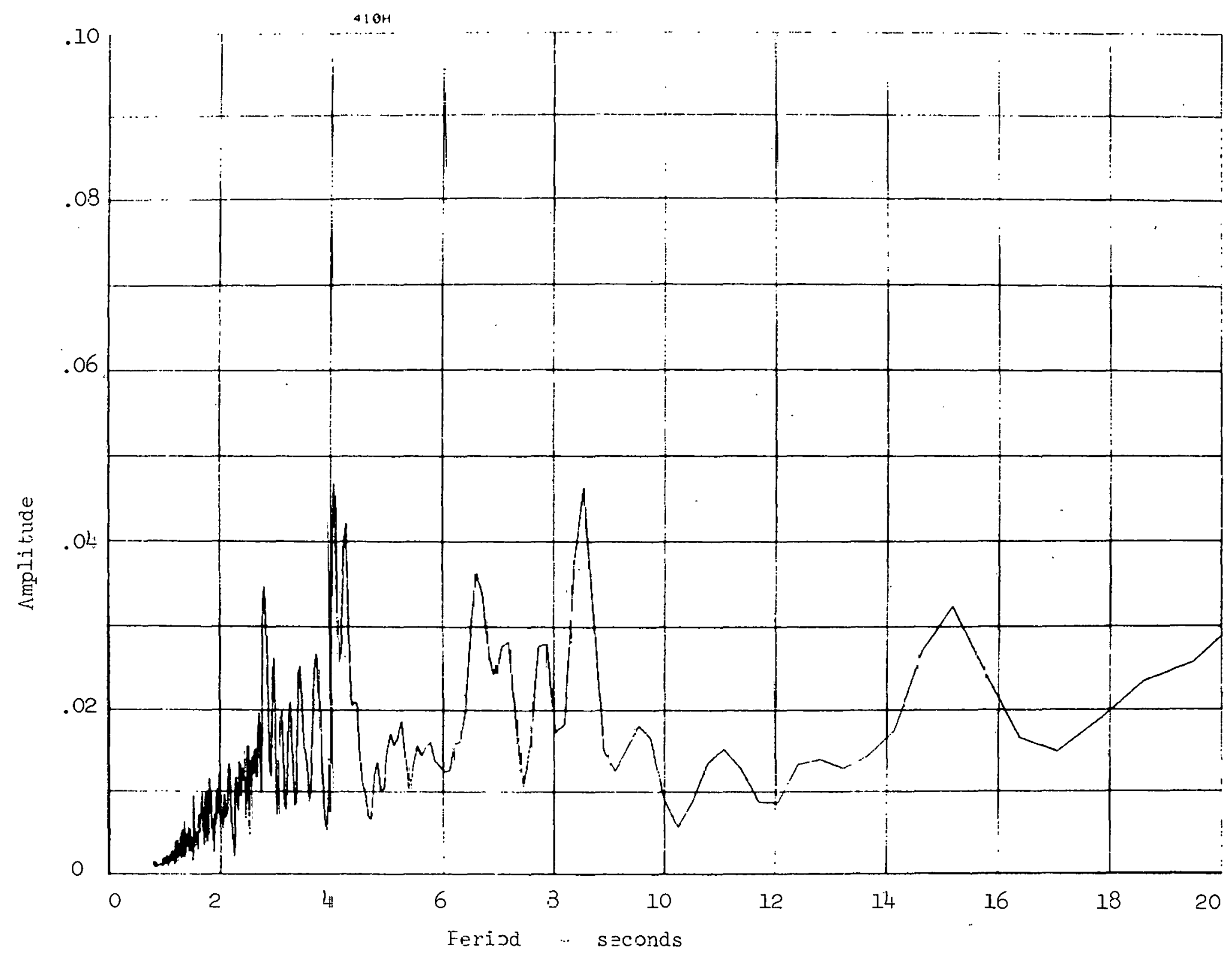




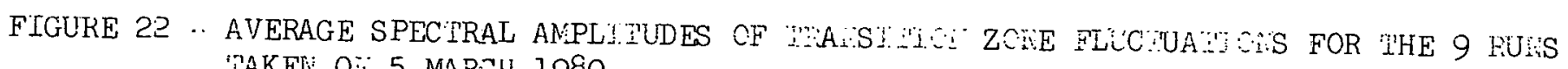
TAKEI: O: 5 MARDII 1980 AUERAGE BPECTRA OF RUNS $485 D-G$ AND $410 D-H$

$\because$

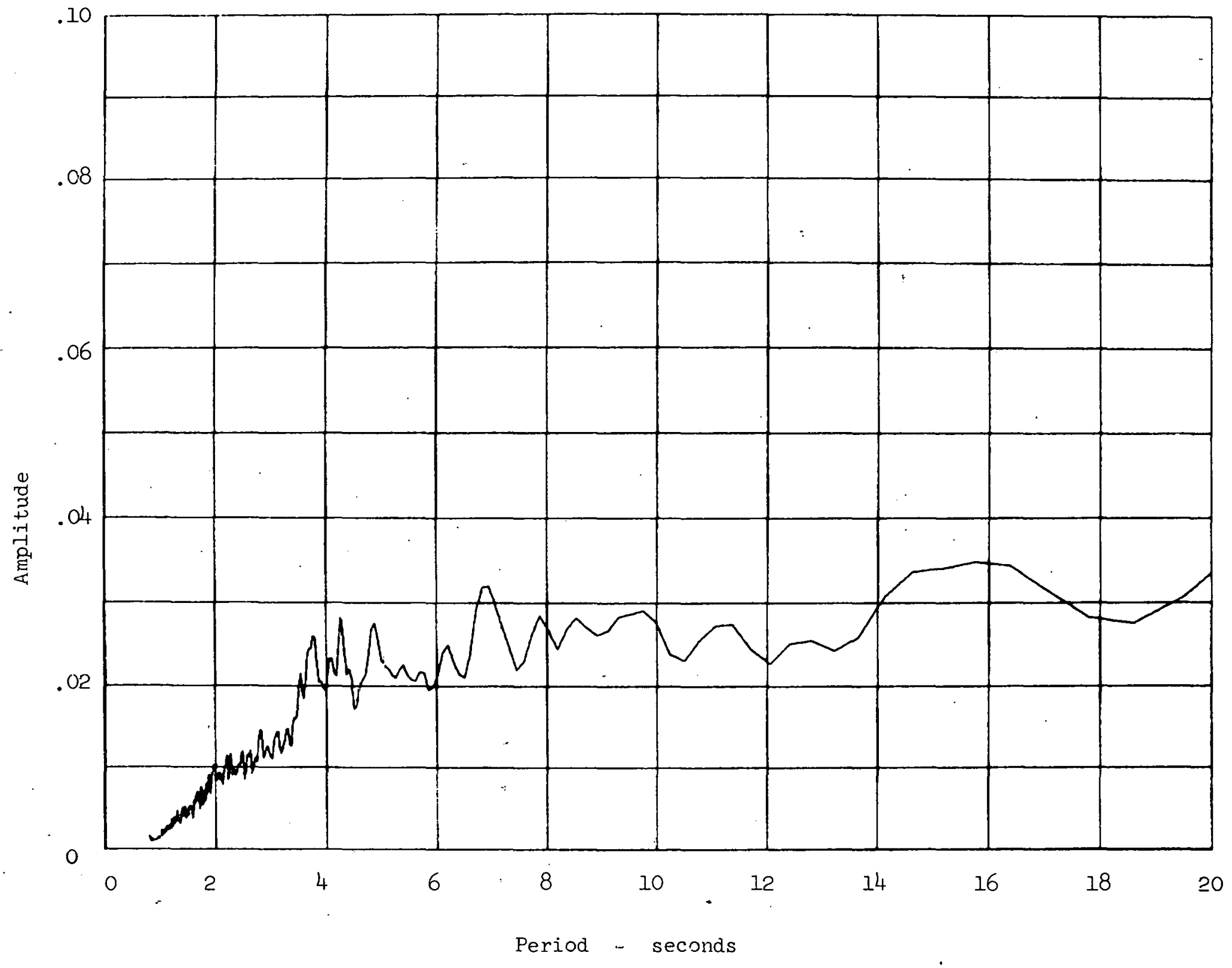


longer than 4 seconds. To prevent aliasing, low pass filters are needed on the data channels. However, the CRTF facility had none whille testing this receiver. The data presented in Figures 9, 20, 21 and 22 all show frequency components with periods shorter than 4.0 seconds. A separate experimental program with a five-tube receiver, similar to the 70 -tube receiver in this test, showed strong fluctuations in the pressure or flow with periods near 0.175 seconds ${ }^{4}$. 'Itherefore, there is slruily evidence that frequency components with periods less then 4.0 secunds did exist in the CRTP data. Once aliasing occurs, it is impas sible to separate frequency components which are real from those which are aliases of higher frequencies. The result of the two second sampling rate is that all CRTF data with periods shorter than about 15 seconds, is suspect (longer periods would be involved only if the high frequency fluctuations are sinusoidal and not transient). Thus, it appears fruitless to try to find correlations with the frequency data from the acoustic measurement and the CRTF data.

The results of this experiment show that periods of high amplitude fluctuation in the transition region position do exist and have relatively high frequencies. However, it has not been possible to identity the events which produce these high amplitude fluctuations. I can only speculate that the high amplitude fluctuations can be initiated by some of the following events: flux distribution changes produced by clouds or quantum jumps in the heliostat positions; sudden changes in the convective cooling of the receiver produced by wind. gusts; transients in the feed water flow produced by valve movements. Any or all of these may be responsible for initiating periods of large 
amplitude fluctuations seen in this experiment.

\section{Summary and Conclusions}

An acoustic technique has been used to measure the movement of the vertical locus of the transition zone between nucleate and film boiling in a prototype solar receiver. It is shown that the data agrees best with the premise that the receiver has a transition zone in which the transition regions in a majority of the individual tubes move in phase with each other rather than moving independently.. This movement of the transition zone can best be described as fluctuations rather than oscillations since there is no indication of preferred or resonant frequencies. The periods of these fluctuations appear to fall at random in a band between three and fifteen seconds. The peak to peak amplitude of the background fluctuation during steady state operation of the receiver is about 0.4 meters for absorbed power levels above $2 M W$. As the absorbed power drops below $2 \mathrm{MW}$, the peak to peak amplitude of these background fluctuations also decreases. The receiver occasionally breaks into higher amplitude fluctuations for reasons which could not be i.ientifien in this experiment. These fluctuations have peak to peak amplitudes up to 2,0 meters and gradually die down, lasting for time periods between 30 and 300 seconds. No particular frequencies could be identified with these high amplitude fluctuations. Oscillations in the receiver controller leading to oscillations in the feed water flow rate can increase the peak to peak amplitude of the background fluctuations to value between 0.8 and 1.0 meters. Based upon these experiments it is impossible to say how a perfectly functioning receiver controller would effect the amplitude and frequency of these fluctuations. The background 
fluctuations were always present at the higher power levels whether the receiver was under manual or automatic control. 


\section{REFERENCES}

1. S. Wolf, K. Chen, T. M. Yang and J. I. Simpson. "Performance Analysis for the MDAC Rocketdyne Pilot and Commercial Plant Solar Receivers." Sandia National Laboratory, SAND 78-8183.

2. D. M. France, R. D. Carlson, T. Chiang, R. Priemer. "CMFInduced Thermal Oscillations Measured in an LMFBR Steam Generator Tube Wall." Argonne National Laboratory, ANL-CT-78-1, October 1977.

3. R. D. Tobin, "Solar Receiver Heat Flux Capability and Structural Integrity." Rocketdyne R-9958, May 1976.

4. John J. O'Hare, private communication. 
DISTRIBUTION:

Unlimited Release

U.S. Department of Energy

Washington, D. C. 20545

Attn: W. W. Auer

G. W. Braun

J. V. Flynn

M. U. Gutstein

J. E. Rannels

Division of Solar Technology

U.S. Departinent of Eneryy

San Francisco Operations Office

1333 Broadway

Oakland, CA 94612

Attn: S. D. E.l.i.iot.

K. W. Hughey

DOE/STMPO

Juite 210

9550 Flair Drive

El Monte, CA 91731

Attn: R. N. Schweinberg

Aerospace Corporation

P. O. Box 92957

Los Angeles, CA 90009

Attn: R. Leatherman

$K$. Zondervan

Babcock \& Wilcox

$20 \mathrm{~s}$. VanBuren Avenue

Barberton, OH 442.03

Attn: 0. W. Durrant

Combustion Engineering, Inc.

1000 Prospect Hill Road

Windesr, Connesticut nfng,

Attn: H. M. Payne

Energy Systems and Technology Div.

General Electric Company

310 DeGuigne Drive

Sunnyvale, CA 94.086

Attn: Sig Wolf (2)

ETEC/STMPO

9550 Flair Drive

Suite 210

El Monte, CA 91731

Attn: K. L. Alder

(2) 


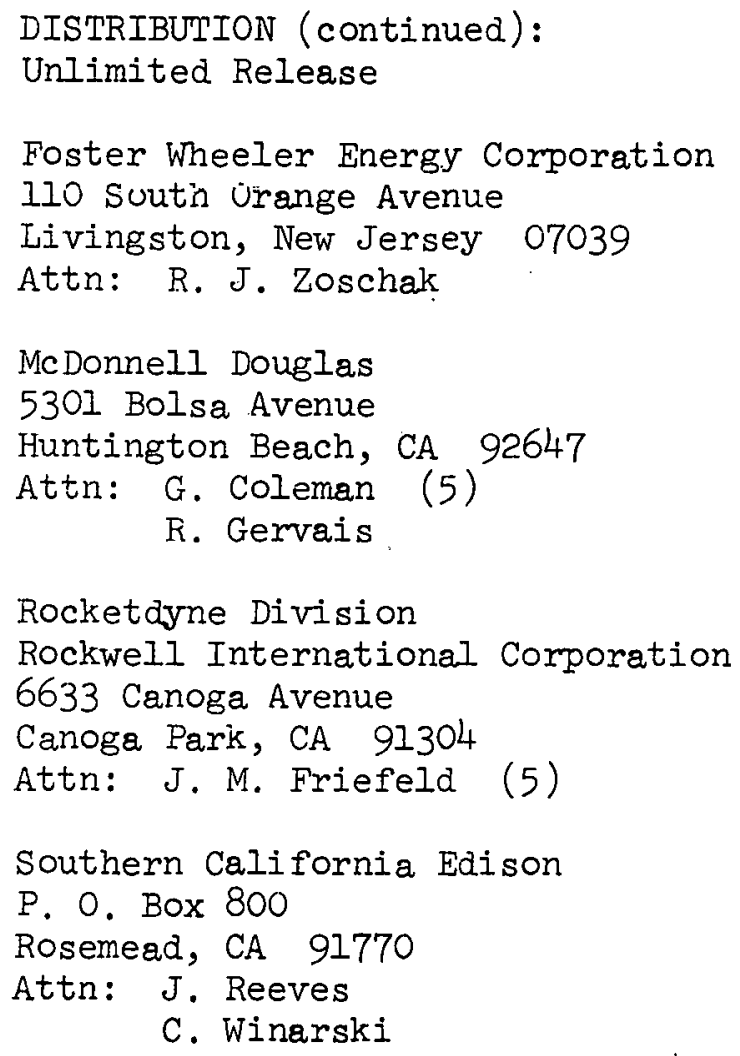

Rocketdyne Division

Rockwell International Corporation 6633 Canoga Avenue

Canoga Park, CA 91304

Attn: J. M. Friefeld (5)

Southern California Edison

P. O. Box 800

Rosemead, CA 91770

Attn: J. Reeves

C. Winarski

Stearns-Roger

P. O. Box 5888

Denver, Colorado 80217

Attn: W. R. Lang

1500 W. A. Gardner

1537 N. R. Keltner

1550 F. W. Neilson

1551 D. W. Ballard

1552 O. J. Burchett

1552 A. G. Beattie (20)

1552 J. A. Kinker

3141 T. L. Werner (5)

3151 W. L. Garner (3)

For: DOE/TIC

4700 J. H. Scott

4710 G. E. Brandvold

4713 B. W. Marshall

4713 I. O. Seamons

4720 V. Dugan

5510 D. B. Hayes

8000 T. B. Cook

Attn: A. N. Blackwell, 8200

8100 W. J. Spencer

B. F. Murphey, 8300 
DISTRIBUTION (continnued):

Unlimited Release

8110 J. F. Barham

Att, $:$ D. J. Bohrer, 8111

J. D. Gilson, 8112

H. M. Witek, 8115

A. T. Jones, 8116

8112 J. W. Liebenberg

8120 W. E. Alzheimer

8122 C. S. Hoyle

8122 J. F. Jones

8124 M. Abrams

8124 R. J. Gallagher

8400 L. Gutierrez

Attn: C. S. Selvage, 8420

D. E. Gregson, 8440

C. M. Tapn, RिL6ก

8410 R. A. Beroody

Attn: J. D. Benton, 8411 .

8444 A. R. Wiliss

S. G. Cain, 8412

8450 R. C. Wayne

8451 . P. J. Eicker

8452 A. C. Skinrood

8453 E. T. Cull (20)

8453 W. G. Wilson

8265 Publications Division

For: TIC (2)

8265 Publications Division

8266 Library and Security Classitication y1v1sion (3)

DOE/TIC (25)

( J. Ilenander, 3154-4) 


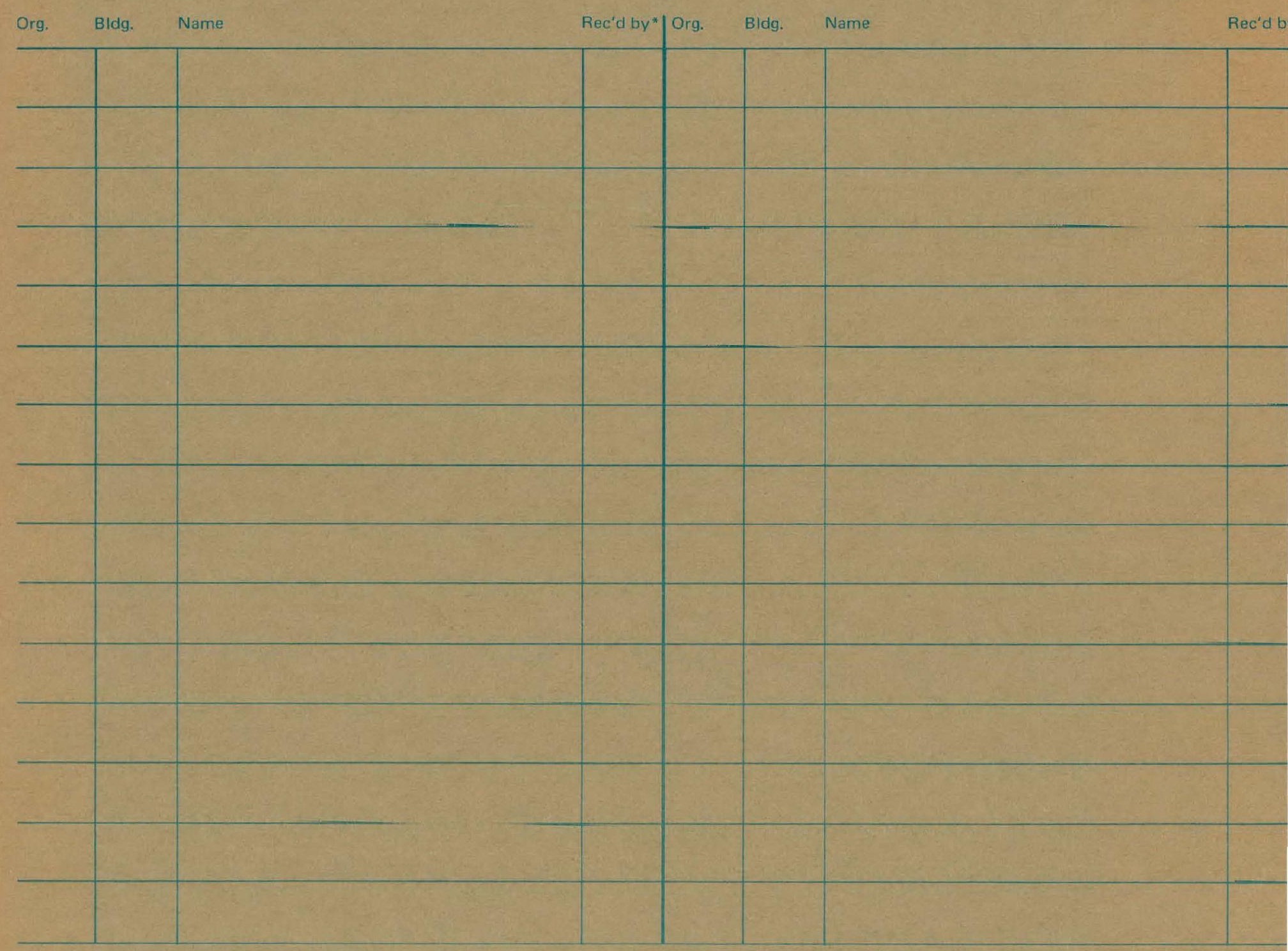

Recipient must initial on classified documents. 